\title{
Co-operative intermolecular kinetics of 2-oxoglutarate dependent dioxygenases may be essential for system-level regulation of plant cell physiology
}

\section{OPEN ACCESS}

Edited by:

Stanislav Kopriva,

University of Cologne, Germany

Reviewed by:

Qing Liu,

Commonwealth Scientific and Industrial Research Organisation,

Australia

Wagner L. Araújo,

Universidade Federal de Viçosa, Brazil

*Correspondence:

Siddhartha Kundu,

School of Computational and Integrative Sciences, Jawaharlal Nehru University, New Mehrauli Road,

New Delhi 110067, India

siddhartha_kundu@yahoo.co.in;

siddha41_sit@jnu.ac.in

Specialty section:

This article was submitted to Plant Metabolism and Chemodiversity, a section of the journal Frontiers in Plant Science

Received: 22 January 2015 Accepted: 19 June 2015 Published: 15 July 2015

Citation:

Kundu S (2015) Co-operative intermolecular kinetics of

2-oxoglutarate dependent dioxygenases may be essential for system-level regulation of plant cell physiology. Front. Plant Sci. 6:489.

doi: 10.3389/fpls.2015.00489

\section{Siddhartha Kundu * \\ School of Computational and Integrative Sciences, Jawaharlal Nehru University, New Delhi, India}

Can the stimulus-driven synergistic association of 2-oxoglutarate dependent dioxygenases be influenced by the kinetic parameters of binding and catalysis? In this manuscript, I posit that these indices are necessary and specific for a particular stimulus, and are key determinants of a dynamic clustering that may function to mitigate the effects of this trigger. The protein(s)/sequence(s) that comprise this group are representative of all major kingdoms of life, and catalyze a generic hydroxylation, which is, in most cases accompanied by a specialized conversion of the substrate molecule. Iron is an essential co-factor for this transformation and the response to waning levels is systemic, and mandates the simultaneous participation of molecular sensors, transporters, and signal transducers. Here, I present a proof-of-concept model, that an evolving molecular network of 20G-dependent enzymes can maintain iron homeostasis in the cytosol of root hair cells of members of the family Gramineae by actuating a non-reductive compensatory chelation by the phytosiderophores. Regression models of empirically available kinetic data (iron and alpha-ketoglutarate) were formulated, analyzed, and compared. The results, when viewed in context of the superfamily responding as a unit, suggest that members can indeed, work together to accomplish system-level function. This is achieved by the establishment of transient metabolic conduits, wherein the flux is dictated by kinetic compatibility of the participating enzymes. The approach adopted, i.e., predictive mathematical modeling, is integral to the hypothesis-driven acquisition of experimental data points and, in association with suitable visualization aids may be utilized for exploring complex plant biochemical systems.

Keywords: 2-oxoglutarate, facial triad, co-operative kinetics, system-level, iron deficiency, non-linear regression

Abbreviations: 2OG, 2-oxoglutarate; AKG, $\alpha$-ketoglutarate; 2OGd, 2OG-dependent; Km, Michaelis-Menten constant; ROS, Reactive oxygen species; RNS, Reactive nitrogen species; MAs, Mugineic acids; ABI, Absicisic acid insensitive. 


\section{Introduction}

The alpha-ketoglutarate (AKG) dependent non-heme Fe (II) dioxygenase superfamily is characterized by variable reaction chemistry and exceptional substrate versatility. This has been attributed to: a relaxed co-ordination geometry for ferrous iron, the formation of an exceptionally reactive, transient ferryl species $[\mathrm{Fe}(\mathrm{IV})=\mathrm{O}]$, and several sequence specific features (Price et al., 2003a,b; Hausinger, 2004; Clifton et al., 2006; Kundu, 2012). The hexadentate interaction with Fe (II) includes the residues His-X-Asp/Glu-Xn-His (facial triad), 2OG, and a displaceable water molecule in a 3:2:1 association (Figures 1A,B). In contrast to the conserved binding profile of these enzymes for iron, the active site amino acids for 2-oxoglutarate and their cognate substrate(s) are distinct and protein specific. Plant AKG-dependent enzymes, participate in flavonoid and alkaloid biosynthesis (catalytic and regulatory), maintain cell architecture (direct, prolyl hydroxylases; indirect, 2S-flavonols), and influence seed dormancy (Kawai et al., 2014). Recent laboratory data also suggests that the o-hydroxylation of feruloyl-CoA (Feruloyl-CoA 6 -Hydroxylase1; EC 1.14.11.) results in compounds that are able to directly facilitate ferric iron absorption in alkaline soils as part of strategy II, i.e., non-reductive assimilation (Kobayashi and Nishizawa, 2012; Schmid et al., 2014).

The presence of a shared double-strand-beta-helical (DSBH) fold, notwithstanding, the members of the 2OG-dependent superfamily of dioxygenases have little in common with regards to the substrates converted and the reaction chemistries deployed. The biochemical significance of this divergence has been highlighted earlier, with the development of a classification schema based on functional homology, and the description of a combinatorial network of AKG-dependent enzymes to accomplish system-level function (Kundu, 2012, 2015). In the former, profile hidden markov models (pHMMs) of enzymes with a similar substrate(s) and/or reaction mechanism were constructed, and utilized to create a repository (DB2OG) of probable 2OG-dependent sequences (Kundu, 2012, 2015). Thus, SULF $\left(N_{\text {SULF }}=3\right)$, a pseudo-family comprising taurine dioxygenase, alkylsulfatase $\mathrm{K}$, and the YSD proteins, are characterized by an additional active site His residue that interacts with a sulfur atom present within the structure of their cognate substrates. Similarly, DSAT $\left(N_{\text {DSAT }}=6\right)$, whose members, viz., the carbapenem- and clavaminate-synthases and select enzymes of the $2 \mathrm{~S}$-flavonol biosynthetic pathways, can facilitate the simultaneous removal of two protons, thereby, inserting a double bond between adjacent carbon atoms. A recently concluded study emphasized the importance of dispersed sub-cellular locales, differential domain distribution, and a variegated substrate profile, in the genesis of transient and task-driven aggregates of $\alpha$-ketoglutarate-dependent enzymes (Kundu, 2015). These results, in a major departure from the one-protein-one-function norm, were established using a combination of mathematical and computational ideas. Thus, while prolyl 4-hydroxylase and asparaginyl hydroxylase can actuate a downstream response to hypoxia, the gibberellic oxidases are responsible for the balance between the highand low-activity GAs (Hedden and Phillips, 2000a,b; Hewitson et al., 2002). However, despite these insights, the pattern and determinants of this synchronized activity remain speculative. The cardinal premise of this work is that an arbitrary, exogenous stimulus can dictate the dynamics of complex molecular networks, and that this stimulus-driven co-operation amongst 2OG-dependent dioxygenases is critical to its role as a systemsplayer. The exposition, vide infra, discusses the development and validation by kinetic parameterization, of an event that could link a perturbation, such as the unavailability of a critical micronutrient, with a stable biochemical modifier of AKGdependent enzymatic activity. The requirement of active site $\mathrm{Fe}(\mathrm{II})$ for this superfamily is invariant, is dependent on the labile iron pool, and can serve as a contributory influence to this real-time clustering.

Iron is an important trace element and in small quantities $(<100 \mathrm{ppm})$, is needed for the proper functioning of several biologically relevant proteins. Although, an oversimplification, the bio-organic-metal interactions for iron maybe categorized as haem- or non-haem based. Deficiency states, which reflect an extinct or unusable labile iron pool (LIP), are referred to as iron/magnesium-dependent chlorosis, with progressive yellow/white discoloration. The LIP, is numerically expressed as the sum of chelated- and free-iron forms, and has traditionally been difficult to estimate directly. Absorption of iron from soil is dependent on the $\mathrm{pH}$, with recovery rates proportional to the fraction of ferrous iron prevalent. This would translate into maximal assimilation if, the hydrogen-ion concentration of the surrounding rhizosphere were in the acidic range $(\mathrm{pH}$ 5.0-6.5 units). The apparatus to facilitate membrane iron transport, at least in plants, appears to have evolved as mutually exclusive events. Strategy I-absorption (reductive), is seen in non-gramineae, whilst, the alternate mechanism (strategy-II) is common in cereal members of the gramineae. This delineation, is however, pedantic with several species exhibiting a dual propensity for either. Thus, non-graminaceous crops are able to reduce iron externally, as well as effect a limited mobilization of $\mathrm{Fe}(\mathrm{III})$ in high $\mathrm{pH}$ soils using coumarins (Rodriguez-Celma et al., 2013; Fourcroy et al., 2014; Schmid et al., 2014). Similarly, poaceae cereals utilize phytosiderophores in a calcareous environment to assimilate ferric chelates, but are competent to implement strategy-I under specialized conditions (flooded paddy fields; Ishimaru et al., 2006; Kobayashi and Nishizawa, 2012).

Predictive mathematical models (static and simulations), may be regarded as abstract representations and may afford mechanistic perspectives into the behavior of complex biochemical systems, of which the AKG-dependent superfamily is a classic exemplar. The initial step is the formulation of an equation with the dependent variable as a linear- or non-linear combination of single- (regression) or multiple(generalized linear models, GLMs; artificial neural networks, ANNs) independent contributing variables. Coefficients are estimated separately using random numbers from known probability distributions (modified Monte Carlo methods) or training/testing datasets (supervised learning). Stochastic simulations provide an unbiased evolution of trajectories despite being analytically intractable. Here, the chemical master equation 

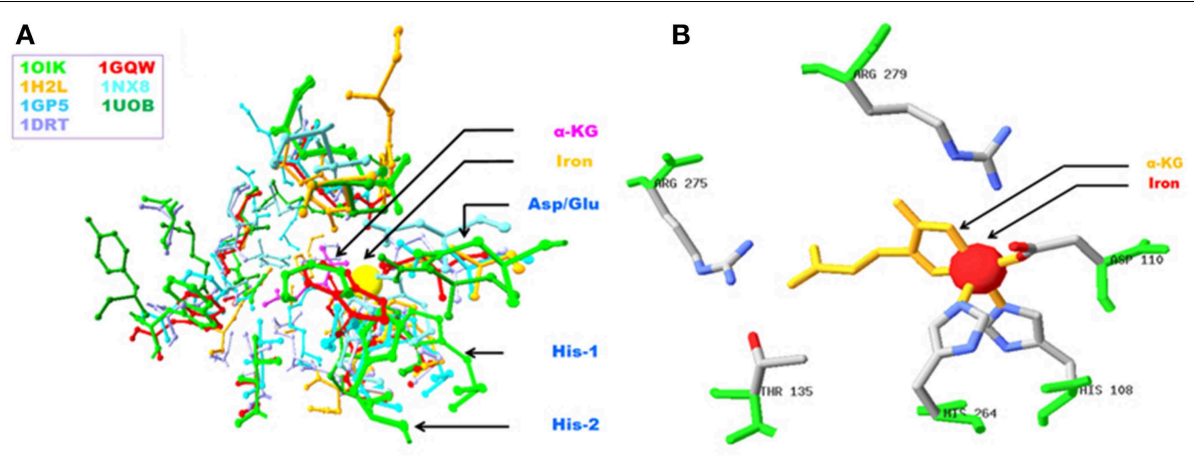

C

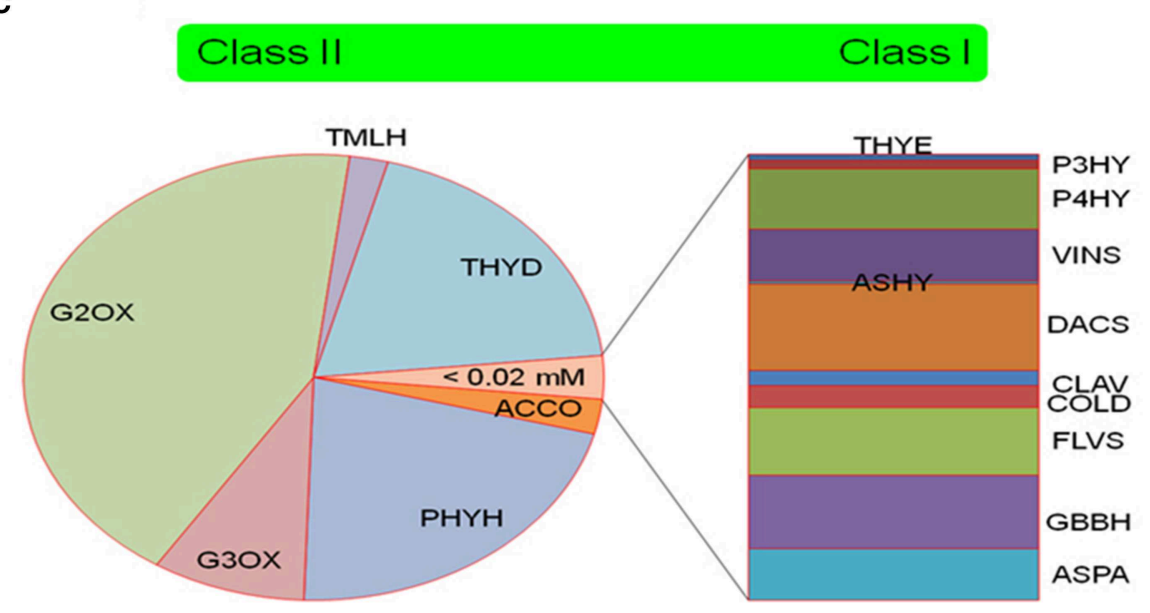

FIGURE 1 | Salient features of 2OG-dependent non-haem Fe (II) dioxygenases. (A) Superposition of active site amino acids of select enzymes (B) Experimentally validated residues of Alkylsulfatase B that participate in iron coordination, 2OG binding, and/or substrate interaction, and (C) Categorization of enzymes based on thresholds, i.e., $K m_{\mathrm{Fe}}$,-values mined from literature. Abbreviations: PDBIDs*: 1OIK, Alkylsulfatase B (Muller et al., 2004); 1GQW, Taurine dioxygenase (Elkins et al., 2002); 1H2L, (Elkins et al., 2003); 1GP5, Anthocyanidin synthase (Wilmouth et al., 2002); 1UOB, Deacetoxycephalosporin synthase (Valegard et al., 2004); 1DRT, Clavaminate synthase 1 (Zhang et al., 2000); 1NX8, Carbapenem C (Clifton et al., 2003).
Nomenclature\# (This work): THYE, Thymine dioxygenase; P3HY, Prolyl 3-hydroxylase; P4HY, Prolyl 4-hydroxylase; VINS, Deacetoxyvindoline 4-hydroxylase; ASHY, Asparagine hydroxylase; DACS,

Deacetoxycephalosprorine synthase; CLAV, Clavaminate synthase I; COLD, Procollagen lysine 5-dioxygenase; FLVS, Flavonol synthase; GBBH, gamma-butyrobetaine dioxygenase; ASPA, Aspartyl-asparaginyl hydroxylase; ACCO, Aminocyclopropanecarboxylate oxidase; $\mathrm{PHYH}$, Phytanoyl CoA hydroxylase; G3OX, Gibberellin 3beta-dioxygenase; G2OX, Gibberellin 2beta-dioxygenase; TMLH, Trimethyllysine hyroxylase; THYD, Pyrimidine-deoxynucleoside 2-dioxygenase. is solved using Gillespie's stochastic simulation and finite state projection algorithms, the methods of -sliding windows and -conditional moments, complex chemical Langevin equation, among several others (Munsky and Khammash, 2006; Gillespie, 2007; Wolf et al., 2010; Hasenauer et al., 2014; Schnoerr et al., 2014).

The reference cell chosen for this study was the root hair of the gramineae (cereals). These short-lived, epidermal extrusions arise from the zone of maturation, and in response to an exigent event, exhibit progressive loosening of the cell wall, elongation, exudation, and complex uptake mechanisms. Biochemically, too, the cell affords a stable cellular milieu, has several specialized 2OG-dependent enzymes, and possesses distinct macromolecules that can maintain iron homeostasis. In this monograph, I have analyzed available kinetic data $\left(K m_{\mathrm{Fe}}, K m_{2 \mathrm{OG}}\right)$ of experimentally validated members of the AKG superfamily, and formulated composite models of the same. The results, both, a posteriori, and computed, when interpreted within the defined framework of the root hair cell, and with pre-computed threshold values, clearly suggest that depressed availability of exogenous iron can result in harmonized cellular 2OG-dependent activity and contribute to the detection and initiation of appropriate countermeasures following a reduction in Fe(II) levels, disjointly, as well as in tandem. Additional findings indicate that reprisal of this novel role, is dependent on a scaffold of interdependent reaction pathways, active site properties of the participating enzymes, and the presence of key convergence nodes. The kinetic data (association, dissociation, and catalysis) utilized, constitute easily verifiable observations, and appears fundamental to the genesis of a dynamic network of select non-haem alpha-ketoglutarate dependent Fe (II) dioxygenases that can accomplish system-level function.

\section{Materials and Methods}

\section{Software and Computational Tools}

Sequences and structural data were downloaded from the Uniprot and PDB (http://uniprot.org; http://www.rcsb.org) 
databases. Distribution of 2OG-dependent catalytic domains of select sequences were predicted using the server module of H2OGpred (http://comp-biol.theacms.in/H2OGpred.html; Kundu, 2012). Miscellaneous computational resources included BRENDA (a repository of biochemical data; Schomburg et al., 2002), the STRAP suite of programs (phylogenetic trees and alignment files; Gille and Frommel, 2001), and the SPDBV (superimposition and visualization of structural data; Guex and Peitsch, 1997). Data processing (parsing, sorting, computing, and formatting) was accomplished using PERL scripts developed in-house.

\section{Datasets and In Silico Experiments}

Enzymes with available kinetic data, catalytic $(\mathrm{Km})$ and binding association $(\mathrm{Ka})$ values for iron and 2-oxoglutarate (Table T1 in Supplementary Material) were compiled and analyzed $\left(D_{\mathrm{Fe}}\right.$, $N=17 ; D_{\mathrm{AKG}}, N=29$ ). Multiple values for an enzyme, with data from either different organisms or variable experimental conditions excluding mutagenesis studies, were averaged. Partitioning, for further computational experiments were in accordance with previously determined ferrous iron levels (Urzica et al., 2012; $T \in\{0.0005,0.001,0.003,0.02\}$ ). Thresholds were also determined using the Monte Carlo method. Numbers were drawn randomly from the open interval $(0,1)$, i.e., $0<x<1$, and scaled with ranges bounded by threshold values. Each experiment was done in triplicate and repeated 500 times. The quasi-datasets obtained were summarized with descriptive statistics. Quartile values of the empirically determined kinetic data of enzymes $\left(q\left(D_{F e}\right)\right)$ and the predicted values for the model $K m_{N L R_{-} F e}$, constituted the complete set of bounds on which inferences about 2OG-dependent behavior were based $(t \in T \cup$ $\left.q\left(D_{F e}\right) \cup K m_{N L R_{F e}}\right)$.

\section{Mathematical Models}

Non-linear regression (NLR) is an established statistical method for predicting values of a dependent variable. Here, the coefficient of determination $\left(R^{2}\right)$ serves as a measure of model selection. There is a fair volume of publically available kinetic data for ferrous iron, 2OG, and $\mathrm{O}_{2}$ (Table T1 in Supplementary Material). Since, molecular dioxygen is an essential reactant and is incorporated into the substrate, the pertinent values were not considered further. Compiled kinetic data points for Fe (II) and 2-oxoglutarate were fitted to several equations and the closest approximate to unity was chosen for further analysis.

\section{Model Evaluation and Derived Kinetics}

Model evaluation was carried out using the chi-squared test $\left(\chi^{2}\right)$. For these calculations the observed values were individual enzyme systems at a threshold value $\left(V_{\text {enzyme }}^{0}(t)\right)$, while the expected value was the behavior of the model at the same threshold $\left(V_{\text {model }}^{0}(t)\right)$.

$$
\chi^{2}=\sum_{i=1}^{i=17}\left\{\left(V_{i}^{0}(t)-V_{\text {model }}^{0}(t)\right)^{2} / V_{\text {model }}^{0}(t)\right\}
$$

Derived velocity maxima for the enzymes was formulated as a modification of the existing Michaelis-Menten (MM) equation:

$$
V_{e n z}^{0}=(0.5)\left(t / K m_{e n z}\right)
$$

$\mathrm{t}:=$ threshold iron concentration

$\mathrm{Km}:=\mathrm{MM}$ constant

enz $\in\left\{\mathrm{NLR}_{\mathrm{Fe}}\right.$, individual enzymes $\}$

\section{Results}

\section{Classification Schema}

The kinetic data for ferrous iron was the basis for a categorization schema (Figure 1C). Class I $(N=11$, high affinity, $\mathrm{Km} \leq 0.02 \mathrm{mM}$ ) enzymes participate in proline hydroxylation, vinca alkaloid synthesis, and the flavonol biosynthetic pathways. Class II $(N=6$, low affinity, $K m>0.02 \mathrm{mM})$ includes the ethylene-forming ACCO, and the gibberellic acid 3- and 2 - $\beta$-dioxygenases. This data suggests that 2OG-dependent dioxygenases have differential affinities for iron, a factor that might translate into a graded response to fluctuating cytoplasmic levels.

\section{Curve Fitting and Model Selection}

A non-linear regression curve for each dataset, i.e., $D_{\mathrm{Fe}}$ and $D_{\mathrm{AKG}}$, was fitted using a 6-degree polynomial (Figures $\mathbf{2 A , B}$ ) as under.

$$
\begin{array}{r}
\mathrm{Km}_{\mathrm{Fe}}=7 E-07 \mathrm{x}^{6}-4 E-05 \mathrm{x}^{5}+0.001 \mathrm{x}^{4}-0.016 \mathrm{x}^{3} \\
+0.141 \mathrm{x}^{2}-0.707 \mathrm{x}+1.556 \\
\mathrm{Km}_{\mathrm{AKG}}=2 E-07 \mathrm{x}^{6}-2 E-05 \mathrm{x}^{5}+0.000 \mathrm{x}^{4}-0.012 \mathrm{x}^{3} \\
+0.126 \mathrm{x}^{2}-0.634 \mathrm{x}+1.277
\end{array}
$$

The coefficient of determination for these curves approximated unity $\left(\mathrm{R}_{\mathrm{Fe}}^{2}=0.981, \mathrm{R}_{\mathrm{AKG}}^{2}=0.964\right)$, whilst the variance $\left(\sigma_{\mathrm{Fe}}^{2}=\right.$ $\left.0.070, \sigma_{\mathrm{AKG}}^{2}=0.025\right)$ of the raw datasets indicate a marginally greater dispersion of the iron affinity data. These parameters were used to select a particular model.

\section{Model Evaluation}

The models are robust (Figure 2C, Tables T2, 3A in Supplementary Material) with $\mathrm{MM}$ constants, $K m_{\mathrm{Fe}} \cong$ $0.644 \pm 1.11 E-05 m M$ and $K m_{A K G} \cong 0.784 \pm 1.47 E-05 m M$, when tested with previously defined ferrous iron concentrations. The performance of the model (NLR$\left.\mathrm{Km} / \mathrm{Ka} \_(\mathrm{Fe}(\mathrm{II}))\right)$ was examined with reference to the chi-squared values in accordance with Equation (1). The data was not significant for lower cytosolic levels of Fe (II), $\left(\left\{\chi_{0.0005}^{2}, \chi_{0.001}^{2}, \chi_{0.0035}^{2}\right\}>\chi_{\text {crit }}^{2} ; p>0.05 ; d f=16\right) \quad$ (Table T3B in Supplementary Material), implying a good correspondence between the NLR for $K m_{F e}$ and kinetic data for various 2-oxoglutarate-dependent enzymes at these concentrations.

\section{Derived Kinetic Data}

Two sets of data points were computed when used in association with Equation (2) and at previously defined threshold $(t)$ values: (a) The distribution of extrapolated reaction velocities of enzymes (Figure 2D, Table T3B in Supplementary Material) and 

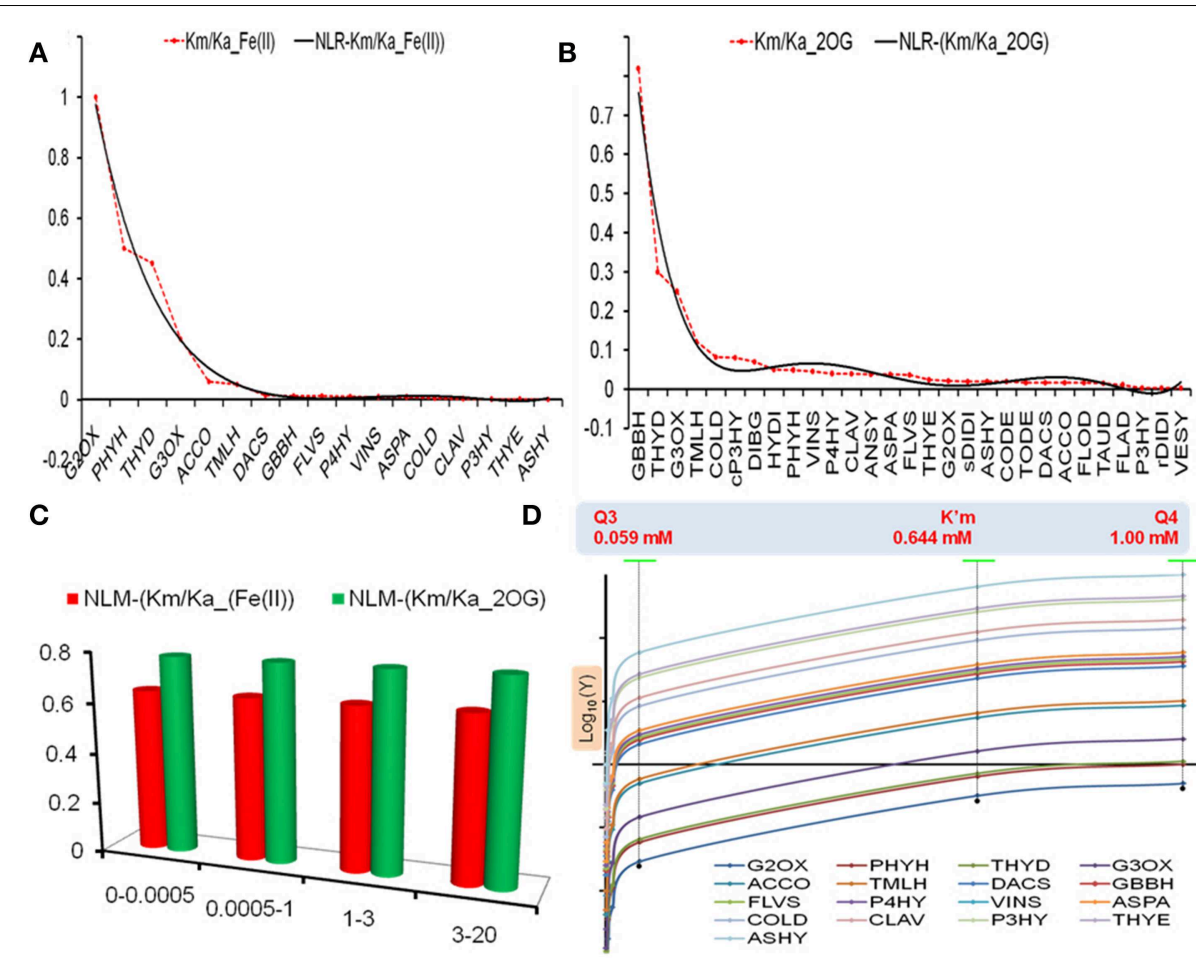

FIGURE 2 | Model selection and analysis. (A,B) Non-linear

regression models of $K m_{\mathrm{Fe}}$ and $K m_{\mathrm{AKG}}$ values in accordance with Equations (3) and (4) (C) Analysis of model robustness using a

Monte Carlo approach, and (D) Predicted $V_{\text {enzyme values at }}^{0}$ different thresholds for select enzymes. Here the ordinate axis is a $\log _{10}$ representation. the model (Table 3C in Supplementary Material), and (b) Chisquared $\left(\chi^{2}\right)$ values comparing the extra- and intra-polated data (observed vs. model) (Tables T3D,E in Supplementary Material).

\section{Catalytic Domain Prediction}

A biological response when graded temporally might be categorized as early (minutes to hours) or late (days), and is characterized by sequential changes in the levels of stored and newly synthesized proteins (Figures 3, 4). An analysis of putative protein products of the transcription factor genes (ABI -3, -4, -5), implicated in the development of absicisic acid (ABA) insensitive mutants ( $N=26$; Table T4A; S1A, S1B, S2 in Supplementary Material) was undertaken to map 2OG function onto these sequences. An examination suggests that the generic AKG domain is present in a majority of sequences $(\approx 57 \%, N=$ $15)$. Interestingly, only putative ABI4- $(100 \%, N=2)$ and ABI5$(\approx 60 \%, N=13)$ sequences possess the same (Figure 5). A distribution of substrate specific specialized regions is tabulated (Table T4B in Supplementary Material; Figure 5).

\section{Discussion}

Compensated iron deficiency is an orchestrated set of molecular steps that cells undertake to reserve essential elements for the most critical of functions. This cellular triage, at least in the roots of grasses, could be the result of initialization-, consolidation-, and termination-level intervention by the
AKG-dependent dioxygenases. Any model would have to be consistent (coefficients are treated as constraints), yet varied (an error term and/or a stochastic event), and function with both intra- and inter-systemic components.

\section{Model Description and Function}

NLR-models are specific for a particular system, accurate, and limited to a single independent variable. Levels of iron in external media have been used previously as a method of classifying the effects on the host cell (iron-saturating, $1 \mu M<$ $t \leq 20 \mu M$; iron-deficiency, $0.5 \mu M<t \leq 1 \mu M$; ironlimited, $t \leq 0.5 \mu M$; Urzica et al., 2012). These concentrations were utilized as reference values for the NLR-models in this study. (Table T2 in Supplementary Material). The labile iron pool, despite its in vivo relevance is relatively inestimable, given the large number of macromolecules and pathways that utilize iron, and was therefore, not considered. There is a thin line between a continually depreciating iron level, as a physiological stimulus to compensatory mechanisms and, as an inducer of stress response pathways. Whilst, the former, entails a metabolic re-distribution mediated by real-time selection (a deficiency state), the latter results in observable structural alterations (a limited state). Although, there is biochemical proof of this delineation (Schikora and Schmidt, 2001a; Urzica et al., 2012), an analytic treatment of this phenomena could provide valuable insights into the nature of this dynamic molecular interplay. 


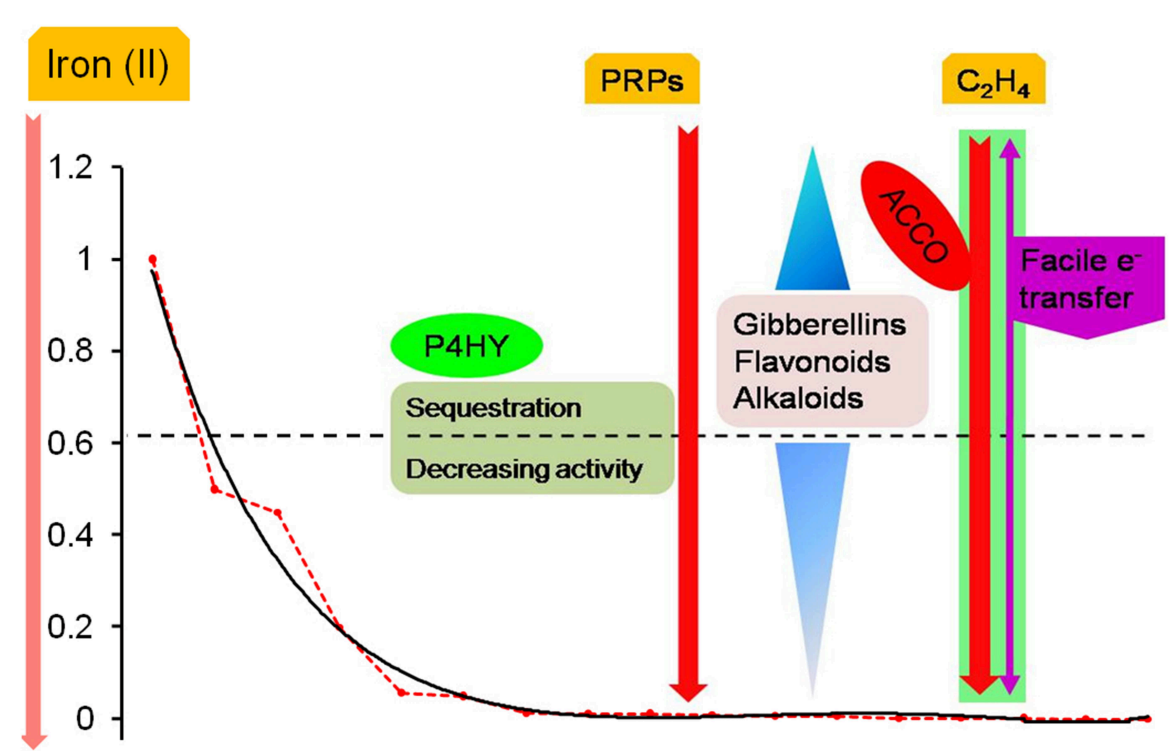

FIGURE 3 | Biochemical machinery during compensated/ early onset iron deficiency. As the cytosolic levels of ferrous iron decline, the differential activity profile of 2OG-dependent enzymes influences the cellular response. These are depicted in reference to the non-linear regression model of predicted iron affinity data $\left(N L R \_K m_{F e}\right)$. Key players include prolyl 4-hydroxylase, despite being almost entirely organellar; secondary metabolites (GAs, bioflavonoids, alkaloids) and monotonic incremental- and decremental-responders; and dual-origin ethylene formation (enzymatic and FETs). Much of this cellular biochemistry is directed toward diminishing the resistance of the cell wall in preparation for growth, development, and the release of rhizosphere influencing metabolites.
Here, I have constructed statistical non-linear regression models of existing biochemical data (Figures 2A,B, Table T2 in Supplementary Material) for both iron (II) and 2-oxoglutarate (NLR-Km/Ka_(Fe(II)); NLR-(Km/Ka_2OG), and proceeded, via inference, to unravel the underlying molecular complexity. The models were evaluated for goodness of fit, measure of dispersion, and robustness. The conserved jelly-roll fold that characterizes this superfamily presents active site residues that interact with $\mathrm{Fe}(\mathrm{II})$ and alpha-ketoglutarate (Figures 1A,B). However, selected data from mutagenesis experiments indicates that, while iron coordination is central to catalytic activity, the demand for $2 \mathrm{OG}$ as a co-substrate is less stringent (Brisson et al., 2012). Many enzymes, have an ancillary need for ascorbate to preserve the active site occupancy of iron (II) $\left(\mathrm{Fe}^{3+} \rightarrow \mathrm{Fe}^{2+}\right)$. The rationale for selecting the NLR_Km/Ka_(Fe(II)) model as a suitable representation was: a) stringency, symbolized by a map equating the coefficient of determination $\left(R^{2}\right)$ of the chosen NLR-models and the datasets to the frequency of iron or $2 \mathrm{OG}$ binding by the common fold, i.e.,

$$
R^{2}\left(D_{z}\right) \mapsto \phi_{z}
$$

$\phi=$ necessity of enzyme modifier to the reaction $\mathrm{z} \in\{\mathrm{Fe}, \mathrm{AKG}\}$

Here, $\phi_{F e}=1$ and $\phi_{A K G}<1$ (by definition); and b) presence of dispersed data. Since the objective was a model which factors in the unequivocal presence of the co-factor or-substrate and accounts for the broad range of $\mathrm{Km}$ values (proportionate to the number of postulated molecular roles), these parameters are perfectly credible as screening metrics. Computations $\left(\mathrm{R}_{\mathrm{Fe}}^{2}>\mathrm{R}_{\mathrm{AKG}}^{2} ; \sigma_{\mathrm{Fe}}^{2}>\sigma_{\mathrm{AKG}}^{2}\right)$, indicate that the affinity of 2OG-dependent enzymes for iron could influence their propensity to work synergistically (Kundu, 2015).

\section{The 20G-Dependent Superfamily as an Interactome}

The dominant character of this transient interaction could have important consequences for cell physiology (Kundu, 2015). The conserved nature of the amino acids of the greek-key motif/ jelly- roll fold that are responsible for coordinating iron, intuitively suggests a tight regulatory mechanism(s). Consequently, iron (II) could function as a critical switch in the genesis of a suitable adaptive response, either involving AKGdependent enzymes exclusively, or in-tandem with downstream mediators (nuclear-cytoplasmic receptors, transcription factors; Bai et al., 2012).

\section{Rapid and Early Response to Ebbing Iron Levels Reduced affinity for iron as a suitable sensor}

2OG-dependent catalysis is characterized by an absolute need for $\mathrm{Fe}(\mathrm{II})$, as opposed to a facultative role for AKG. Despite this, it was surprising to note that the affinity spectrum for iron spans three orders of magnitude $\left(\log K m_{\text {max }} / K m_{\text {min }} \cong 3.301\right.$; Table T1A in Supplementary Material). Given the sequence and structural variants thereof, this was not entirely unexpected. This finding, however, implies a lack of robustness, or reciprocally, a heightened sensitivity to fluctuations in cytosolic iron among low 


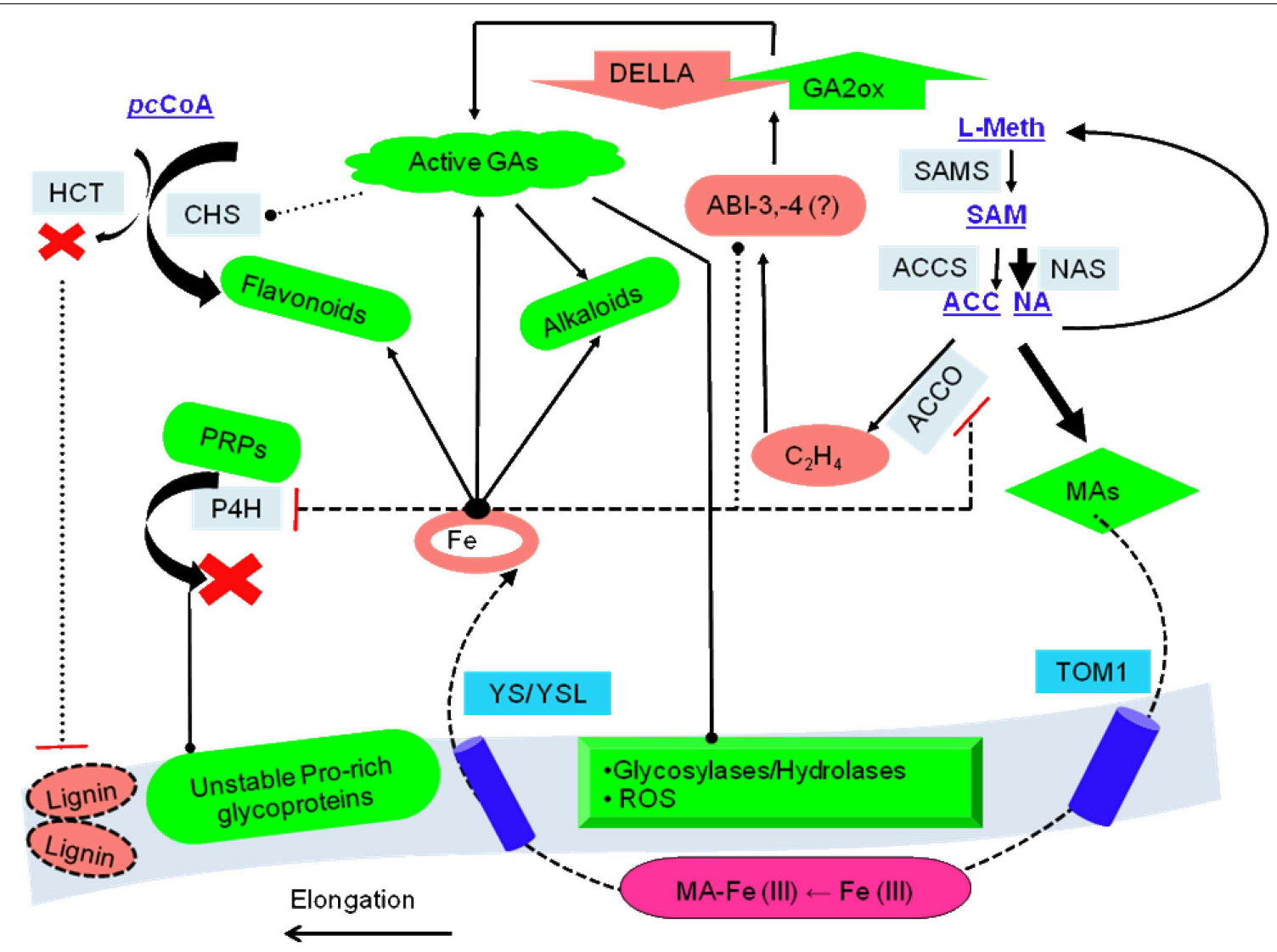

FIGURE 4 | Consolidated model of 2-oxoglutarate sensing and actuation in root hairs of graminaceous plants. The role of intermediate metabolites of two major metabolic pathways: SAM to either ACC or NA, and $\mathrm{p}$-coumaroyl-CoA(pCC) to either naringenin (flavonoids/isoflavonoids) or lignins, is presented. These ideas are centered on the non-catalytic electron transfers that characterize ACCO, sensor binding and information transfer by transcriptional factors, and kinetic data (existent and predicted). The model predicates root hair elongation as a function of cell wall loosening with concomitant iron -chelation and -pool restoration. Key: regulation (...), low activity (----). Abbreviations: PRPs, proline-rich glucoproteins; TOM1, transporter of the major facilitator superfamily; YS/YSL, yellow-stripe/ yellow-stripe like; ROS, reactive oxygen species; L-meth, L-methionine; pDELL, proteins with the N-terminal DELLA domain (RGA, RGL1, GAI, RGL2, RGL3); ABI, Absicisic acid insensitive; CHS, chalcone synthase; HCT, hydroxycinnamoyl-CoA: shikimate/quinate hyroxycinnamoyl-CoA transferase; pcCoA, p-coumaroyl-CoA; MAs, mugineic acids. affinity (Class II), members of this superfamily. A comparison between the Michaelis-Menten (MM) constant for the model (NLR-Km/Ka_Fe(II)) and GA2ox $\left(K m_{\max }\right), 0.644$ vs. $1.00 \mathrm{mM}$, indicates that the reduced activity of this enzyme may be the earliest effected modality of the root hair cell in its reaction to iron deprivation. Since GA2ox is responsible for the catabolism of the bioactive gibberellic acids, the belowpar activity $\left(V_{G 2 O X}^{0}(0.644) \cong(0.3) V_{\text {max }} ; V_{G 3 O X}^{0}(0.644) \cong\right.$ (1.6) $V_{\max }$ ) (Table T1 in Supplementary Material, Figure 2D), would result in the accumulation of GAs. This primaryand secondary- (increased ubiquitinylation of DELLA-domain proteins; early-gene hypothesis; Zentella et al., 2007) inflation of GA levels could result in a bias favoring flavonoid biosynthesis in competing substrate pathways (Figures 3, 4), and alkaloid metabolism.

\section{Priming the cell for compensatory redirection}

The phase of iron deficiency $(0.0005-0.001 \mathrm{mM})$ is characterized by a low predicted $\mathrm{Km}$ value for the model
$\left(V_{N L R \_K m(F e)}^{0}(0.001) \leq(0.0008) V_{\max }\right)$ and is as remarkable for its biochemical re-routing, as is its inertness to any major cytoskeletal alterations. The predicted enzyme velocity values however, suggest that with the exceptions of asparagine hydroxylase $\left(V_{A S H Y}^{0}(0.001)=V_{\max }\right)$, and thymine dioxygenase ( $\left.V_{\text {THYE }}^{0}(0.001) \cong V_{\max } / 2\right)$, the catalytic transformation is sub-optimal $\left(V_{\max }^{0}<V_{\max } / 2\right)$ for every other Class I member. Interestingly, both these enzymes are important mediators of nuclear-signal transduction. While, ASHY fulfills this role in association with $\mathrm{P} 4 \mathrm{HY}$ to impel a cellular response to hypoxia, THYE does so indirectly by catalyzing the oxygen-sensitive committed first reaction in the synthesis of the modified base J (Yu et al., 2007; Vainio et al., 2009). Significant though these changes maybe, the shuffling of metabolic pathways to preserve critical function is probably hormonal in origin (cascadic, non-local, low specificity, and self-limiting).

A major convergent node to emerge during this phase is the loss of integrity of the cell wall. This cytoskeletal entity, despite its de facto physiological role in transport is remarkably predisposed 


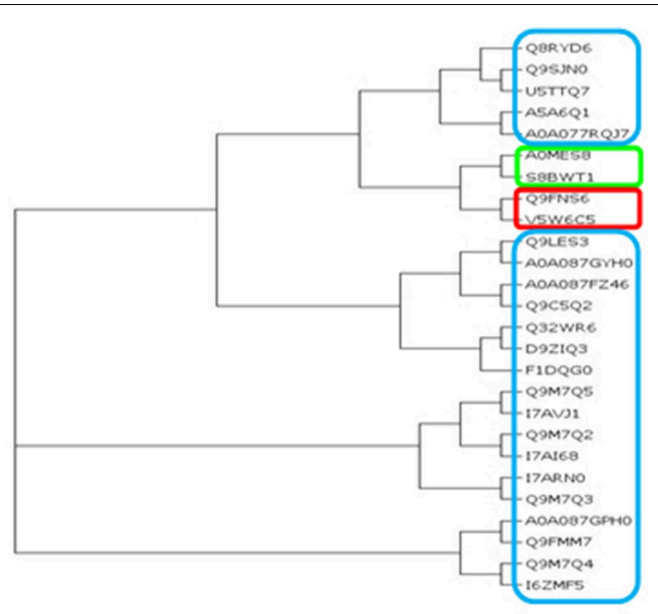

\section{$A B \mid 3(B 3-T F s)$}
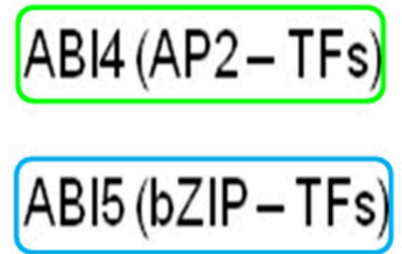

\begin{tabular}{|c|c|c|c|c|c|c|c|c|c|c|c|c|}
\hline & & & & & & & & & & & & \\
\hline Q9FNS6 & - & - & $\cdot$ & - & + & $\cdot$ & $\cdot$ & + & $\cdot$ & $\cdot$ & $\cdot$ & 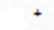 \\
\hline V5W6C5 & - & + & - & - & - & - & - & - & - & + & + & + \\
\hline AOMESB & + & - & - & - & - & - & - & + & - & - & - & \\
\hline SBEWT1 & + & + & + & - & - & + & - & + & + & - & - & \\
\hline QBRYDS & + & - & - & - & - & - & - & - & + & - & - & - \\
\hline Q.9M7Q.5 & + & + & - & - & + & - & - & - & + & - & - & \\
\hline$Q_{Q 9 C 5 Q 2}$ & - & - & - & + & + & - & - & - & + & + & - & \\
\hline Q9FMM7 & - & - & - & - & - & - & - & + & + & + & - & \\
\hline Q9M7Q2 & + & $\cdot$ & + & $\cdot$ & + & $\cdot$ & $\cdot$ & - & - & $\cdot$ & $\cdot$ & \\
\hline Q9M7Q3 & - & - & - & - & - & - & - & - & + & - & - & - \\
\hline Q.9M7Q4 & - & - & - & + & + & - & - & - & - & - & + & 8 \\
\hline Q.95 NO & + & - & - & - & + & + & - & + & - & + & + & \\
\hline Q9LES3 & + & - & - & + & - & - & + & - & + & - & - & $\theta^{-}$ \\
\hline A.5A6Q1 & + & + & + & - & + & - & - & + & - & - & - & $\theta^{-}$ \\
\hline 17AVII & - & - & - & $\cdot$ & + & - & - & - & + & - & $\cdot$ & \\
\hline 16ZMF5 & - & - & - & + & + & - & - & - & + & - & - & \\
\hline I7ARNO & + & + & - & - & - & - & - & + & - & - & - & $\theta^{-}$ \\
\hline 17A 158 & - & - & - & - & + & - & - & - & - & - & - & \\
\hline U5TRQ7 & - & - & + & + & + & + & - & - & - & + & - & \\
\hline Q32WF6 & + & - & + & - & + & + & - & - & + & - & - & \\
\hline D9zio3 & + & - & - & + & + & - & - & - & + & - & - & \\
\hline$F 10 Q 90$ & + & + & + & - & - & - & - & - & - & + & - & \\
\hline$A 04077 R 0,77$ & + & - & - & + & + & - & - & + & - & - & - & \\
\hline AOAOB $7 F Z 45$ & + & - & - & + & - & - & - & - & + & - & + & \\
\hline$A 0 A 087 G \mathrm{PHO}$ & + & + & + & + & + & - & + & - & + & + & + & \\
\hline AOA0B7GYHO & - & - & - & - & - & - & - & - & - & - & - & \\
\hline
\end{tabular}

FIGURE 5 | Analysis of the protein products of Absicisic-acid insensitive ( $\mathrm{ABIs}-3,-4$, and -5 ) mutant causing genes. These function as integrators of stimulus-responsive cascades. This is in part, due to a bimodal binding pattern, i.e., cytosolic elements and DNA-binding, that typifies many of these proteins. Evidence indicates that the non-catalytic ABls form intra- and inter- protein networks, and regulate their cytosolic-nuclear levels by forming self-limiting feedback mechanisms. Domain analysis of these sequences for 2-OG binding motifs suggests the presence of basic (DNA-binding, B3; AP2; bZIP) and acidic amino acids which may coordinate iron and/or form protein-protein interactions with well characterized 2-oxoglutarate members. (\#) Abbreviations: Kundu, 2012: ALKB, Alk-B like demethylase;
ARGI, Arginine hydroxylase; ASPA, Aspartyl:Asparaginyl hydroxylase; CHLO, Chlorination; CLAS, Clavaminate synthase; COLY, Collagen lysyl dioxygenase; $\mathrm{CP} 3 \mathrm{H}$, Collagen prolyl 3-hydroxylase; $\mathrm{CP} 4 \mathrm{H}$, Collagen prolyl 4-hydroxylase; CYCL, Cyclization; DACS, Deacetoxycephalosporin-C synthase; DSAT, Desaturase; ECTO, Ectoine hydroxylase; FLAV, 2S-Flavones; GBBH, $\gamma$ - butyrobetaine hydroxylase; GIAC, Gibberellic acid; HILY, Histone lysyl demethylase; HP4H, Hypoxia prolyl 4-hydroxylase; HYOS, Hyoscyamine; NUHY, Nucleotide/side hydroxylase; OGFD, Eukaryotic initiation factor $2 \alpha$ (elF2 $\alpha$ ); PHYT, Phytanoyl-CoA; SULF, Sulfate cleaving; TFDA, 2,4-Diphenoxyacetic acid metabolizing; THYD, Thymidine dioxygenase; THYE, Thymine dioxygenase; XANT, Xanthine hydroxylase. to biochemical maneuvering. Three major classes of 2OGdependent molecules in graminaceous roots are likely to effect the utilization of iron by switching between sub- (reversible) and supra- (committed) threshold states. The cumulative actions of the elevated bioactive GAs (Hedden and Phillips, 2000a,b), continued synthesis of ethylene, and the sequestered prolyl 4-hydroxylase, result in the activation of several anti-parallel reaction pathways. Cell wall loosening is probably implemented directly by GA- and ethylene-activated resident hydrolases or expansion proteins (Carpita and Kanabus, 1988; Cho and Cosgrove, 2002; Cui et al., 2005), or by a deficient PRP yield
(Hijazi et al., 2014), and indirectly, consequent to a flux in the direction of the bioflavonoid synthetic pathway (Figures 3, 4). These pro-enervating signals are kept in check by the potent antioxidant activity of the polyhydroxylated 2S-flavonols (Kumar and Pandey, 2013).

Ethylene, a powerful gas acts as dominant negative molecular regulator of senescence and ripening. At the observed iron (II) concentrations for compensation $(<0.001 \mathrm{mM})$, the major ethylene synthesizing enzyme,1-amino-cyclopropanecarboxylate-oxidase (ACCO, EC1.14.11.4), has almost null activity $\left(V_{A C C O}^{0}(0.001)<(0.008) V_{\max }\right)$. Despite this, facile 
electron transfers (FETs) aided by the relatively more compact ACC's continued presence at the active site (Zhang et al., 2004) and its proximity to $\mathrm{O}_{2}$, results in an almost unabated egress of ethylene $(\approx 0.35 \mathrm{~mol}$; Rocklin et al., 2004; Mirica and Klinman, 2008). This non-enzymatic transformation also results in activated molecular dioxygen diffusing out of the active site, and a progressive increase in flux of the precursor SAM toward the synthesis of the mugineic acids (Ma et al., 1995) (Figure 3).

Yet another objective accomplished by these pathway rearrangements is the provision of a readily accessible nitrogen source. Bioflavonoids and alkaloids are important secondary metabolites synthesized in plants (Zhang et al., 2012; Long et al., 2013). 2OG-dependent enzymes are known to impact the tropane, isoquinoline, and monoterpenoid-indole classes of alkaloids (Table T1A in Supplementary Material) (Matsuda et al., 1991; Vazquez-Flota et al., 1997; Hagel and Facchini, 2010a,b). Predicted affinity data for individual enzyme systems $\left(V_{\text {FLVS }}^{0} \cong(56) V_{\text {max }} ; V_{\text {VINS }}^{0} \cong(74) V_{\text {max }}\right.$, ) demonstrate that at these levels of ferrous iron, secondary metabolite synthesis is still functioning above par (Figures 3, 4).

\section{Structural changes in uncompensated iron deficiency}

Empirical data (Urzica et al., 2012) suggests that as the exogenous and thereby, cytosolic iron falls to less than $0.0005 \mathrm{mM}$, there is a total and irreversible loss of cell wall integrity. The molecular actuator(s) of this watershed event are debatable, with an imbalance, rather than the perturbation of any isolated analyte, being causal.

The gibberellic acid (GA) mediated flux and consumption of p-Coumaroyl-CoA (pCC) in favor of 2S-flavanol synthesis at higher cytosolic ferrous iron levels constitutes a fundamental branch point. Whilst, the compromised monolignol levels may accelerate cell wall weakening, the routing of pCC toward other pathways, notably coumarin synthesis via feruloyl-CoA, would equip the cell with another means to chelate $\mathrm{Fe}(\mathrm{III})$ in the presence of a high $\mathrm{pH}$ soil (Kai et al., 2008; Schmid et al., 2014). However, since, these reactions are $\mathrm{Fe}(\mathrm{II})$-dependent, the continually dipping levels of this essential trace element could result in the nearcomplete cessation of activity of 2S-flavanol synthetic enzymes $\left(V_{F L V S}^{0}(0.001) \cong(0.05) V_{\text {max }} ; V_{F L V S}^{0}(0.0005) \cong(0.02) V_{\text {max }}\right)$. The physical presence of ferrous iron at the active site of high affinity 2OG-dependent catalysts might also be expected to contribute to the formation of free radicals in a manner reminiscent of ACCO activity. FETs in many of these enzymes could convert $\mathrm{O}_{2}$ into potent sources of ROS/RNS (Muller et al., 2009). Reactive -oxygen and nitrogen species are a group of related free radicals, vide., hydroxyl- $\left(\mathrm{OH}^{-}\right)$, superoxide- $\left(\mathrm{O}^{2-}\right)$, nitrite- $\left(\mathrm{NOO}^{-}\right)$, and peroxynitrite- $\left(\mathrm{ONOO}^{-}\right)$anions. The predicted velocity maxima, $\left(V_{N L R \_K m(F e)}^{0}(0.0005) \cong(0.0004) V_{\max }\right)$, hints at the possibility that such an episode may indeed transpire.

This unchecked increase in the concentration of ROS/RNS consequent to (i) the diminishing pool of free-radical scavenging bioflavonoids, and (ii) residual enzyme FETs, could constitute the final insult to the integrity of the cell wall propelling it toward a state of null resistance, thereby, (a) expediting the growth and elongation of immature zonal cells with the formation of root hairs, (b) nourishing newly formed tissues by depleting the alkaloid reserves, and (c) expelling exudates enriched in the mugineic acids ( $2^{\prime}$-DMA, MA, $3^{\prime}$-HMA, $3^{\prime}$-hydroxymugineic acid; $3^{\prime}$-EMA, $3^{\prime}$-epihydroxymugineic acid) into the surrounding rhizosphere. These can, then solubilize the ferric iron and effect an inward transport mediated by the proteins YS/YSL (yellow stripe/yellow stripe like) restoring cytosolic iron (Nakanishi et al., 2000; DiDonato et al., 2004; Koike et al., 2004; Nozoye et al., 2011) (Figure 4).

\section{DNA Binding Proteins as Long Term Signal Transducers of Iron Deprivation}

An emerging line of evidence suggests under conditions of abiotic stress such as cold, drought, and/or excessive salinity, the AP2 family of transcriptional regulators function to mitigate the effects of the noxious stimulus by slowing growth and preserving resources (Achard et al., 2008; Magome et al., 2008; Zawaski and Busov, 2014). Absicisic acid (ABA) insensitive mutants, have variations in defined loci and code for phosphatases (ABIs$1,-2)$, transcription factors (ABIs $-3,-4,-5)$, and proteins with miscellaneous function (ERA -1, -3), that allow them to thrive at concentrations that favor seed dormancy (Koornneef et al., 1984; Cutler et al., 1996; Leung et al., 1997; Finkelstein et al., 1998; Alonso et al., 1999; Brady et al., 2003). ABI3 (IDEF2, iron deficiency 2), a B3 containing modulator may bind to divalent cations $\left(\mathrm{Fe}^{2+}, \mathrm{Cu}^{2+}, \mathrm{Ni}^{2+}\right)$ directly, and sense the proportion of iron. This is translated into a differential signal for downstream gene regulation (Kobayashi et al., 2007, 2010, 2012).

In this work although the sample size was small, none of the putative $A B I 3$ sequences possess the AKG catalytic region. ABI4, a member of the AP2-family of transcriptions factors (TFs), may function by (a) binding to and upregulating a GA2ox, and/or (b) proteasomal degradation of key DELLA proteins (Finkelstein et al., 2011; Cantoro et al., 2013). ABI5, a basic zipper transcription factor (bZIP), has a conserved alanine residue which interacts with $\mathrm{ABI} 3$. ABI5 mutants exhibit increased tolerance to osmotic stress $(\mathrm{NaCl}$ and mannitol; Ogo et al., 2007; Tezuka et al., 2013). Since, a majority of ABI5 sequences also contain the AKG domain, it is reasonable to infer that the concentration of ABI5 is governed by co-factor dependence, which in turn may effect formation/stability of the ABI3-ABI5 complex, and the transactivation of the IDE response genes, thereof.

\section{Concatenating the Temporally Distinct Pathways}

Whilst, the 2OG-dependent response has its fulcrate on the presence of pre-formed molecules, and is in most cases selflimiting, there is little clarity on the contribution of TFs in a unified model. One possibility could be the tight binding of an AKG-dependent member to a TF. As levels of ferrous iron plummet, this interaction could become less restrictive due to allosteric mechanisms. In such as scenario, the TF could then enter the nucleus and execute the upregulation of other genes (Itai et al., 2013). Another attractive hypothesis could be that some of these TFs (ABIs $-3,-4$, and/or -5 ) may possess latent 


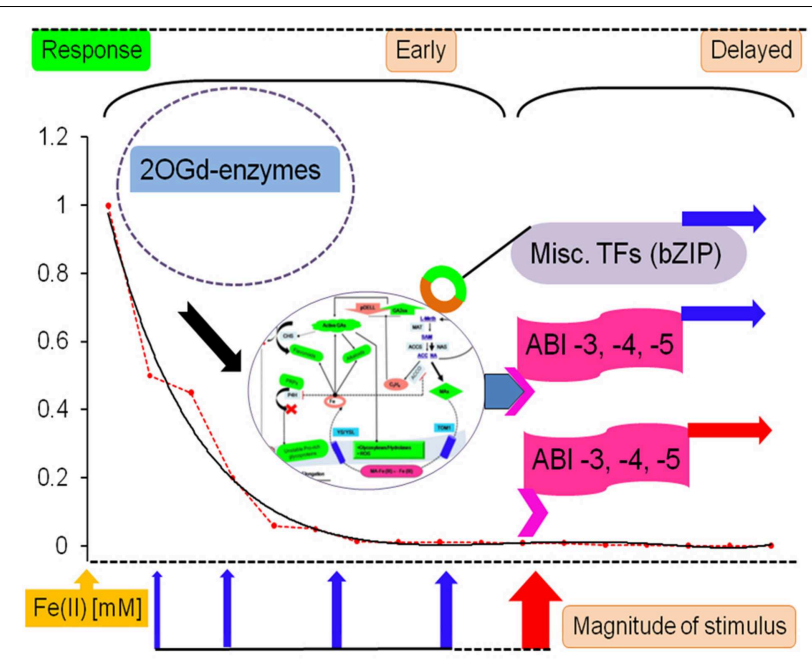

FIGURE 6 | AKG-dependent enzymes as a molecular glue in the response to iron deficiency. A key threshold value for cytosolic ferrous iron, $0.0005 \mathrm{mM}$, governs the response route of the root cell. Stimuli leading to steady-state levels above this, elicit attenuated counter-measures, that are limited to metabolic redirection. However, below this value structural alterations are common. These long-term changes are mediated by the transcription factors $(\mathrm{ABI}-3,-4,-5)$ and can be influenced both, by an instant deprivation of great proportion or an uncompensated threshold cross-over. TFs are also thought to be evoked in previous stages by the phytohormones (Schikora and Schmidt, 2001b). Abbreviations: 20Gd, 2-oxoglutarate-dependent; TFs, transcription factors; Fe (II), ferrous iron; $\mathrm{ABI}$, absicisic acid insensitive.

2OG-dependent activity and/or, may present a favorable proteinprotein interaction surface with other 2OG-dependent enzymes. An AKG-domain analysis of putative 2OG-dependent ABIs (Figure 5; Table T4B in Supplementary Material), reveals that the histone demethylase (HILY), hypoxia prolyl 4-hydroxylase $(\mathrm{HP} 4 \mathrm{H})$, and the 2-oxoglutarate and iron-dependent dioxygenase domain containing 1 (OGFOD1) domains are among the most frequent ( $>$ q3). These domains, as components of characterized enzymes are well established in literature as mediators of cytosolic-nuclear factor shuttling that terminates in transcriptional regulation of stress inducible genes (Myllyharju, 2008; Wehner et al., 2010; Thinnes et al., 2014).

From the above data it does seem conceivable that TFs could indeed serve as a critical component of a systems level 2OG-dependent reaction to iron-deficiency, both as a sensor and actuator of a late iron-deficiency response (Kobayashi et al., 2012). This advanced involvement of the transcriptional apparatus, directly (IDEF2) and/or indirectly (ABI4, ABI5), would have to be synchronized with the early loss of GA2ox

\section{References}

Achard, P., Gong, F., Cheminant, S., Alioua, M., Hedden, P., and Genschik, P. (2008). The cold-inducible CBF1 factor-dependent signaling pathway modulates the accumulation of the growth-repressing DELLA proteins via its effect on gibberellin metabolism. Plant Cell 20, 2117-2129. doi: $10.1105 /$ tpc. 108.058941 activity, secondary metabolite accumulation, and compromised cell wall integrity. This could ensure new and continued elongation of root hairs, whilst transporting Fe (III)-MA chelates internally (Figure 6).

\section{Conclusions}

Previous work has purported the origin of a stimulusdriven dynamic network of 2-oxoglutarate dependent enzymes to accomplish system-level function, a novel role for this superfamily. The multitude of substrates and reactions that characterize these catalysts were deemed responsible for this expression. The models and analysis presented, vide supra, provide proof-of-concept of the assertion that a combinatorial assembly of 2OG-dependent enzymes can manifest within the cellular milieu and negate the effects of an external perturbation, such as the deprivation of an important micronutrient. The co-operative intermolecular kinetics of this association results in directed quasi-pathway(s) with: feedback regulation, compartmentalization, and product utilization, as component modifiers. Although the model(s) are sufficiently coarse-grained, details of the underlying stoichiometry (product(s), reactant(s)) remain elusive. The measure of flux, of these metabolites, too, is not elaborated on. Further analysis to elucidate these details could be undertaken, as could be the deciphering of the kinetic constants from available atomic-scale data.

\section{Author Contributions}

SK collated all data, carried out the computational analysis, formulated and refined the models, wrote all relevant code, and the manuscript.

\section{Supplementary Material}

The Supplementary Material for this article can be found online at: http://journal.frontiersin.org/article/10.3389/fpls.2015. 00489

\section{Table T1 | Kinetic data for Fe(II) and 2-oxoglutarate (T1.xlsx).}

Table T2 | Datasets of computational experiments using the Monte Carlo protocol (T2.xlsx).

Table T3 | Robustness of NLR models across predefined thresholds of cytosolic iron (T3.xlsx).

Table T4 | Distribution of catalytic domains in select sequence homologs of proteins responsible for ABA insensitivity (T4.xIsx).

S1A, S1B | Computed HMMER details of domains in Table T4 (*.zip, *.txt).

S2 | $A B I-3,-4$, and -5 sequences in fasta format (*.txt). 
tetramer. J. Biol. Chem. 272, 17342-17348. doi: 10.1074/jbc.272. 28.17342

Annunen, P., Koivunen, P., and Kivirikko, K. I. (1999). Cloning of the alpha subunit of prolyl 4-hydroxylase from Drosophila and expression and characterization of the corresponding enzyme tetramer with some unique properties. J. Biol. Chem. 274, 6790-6796. doi: 10.1074/jbc.274.10.6790

Armstrong, L. C., and Last, J. A. (1995). Rat lysyl hydroxylase: molecular cloning, mRNA distribution and expression in a baculovirus system. Biochim. Biophys. Acta 1264, 93-102. doi: 10.1016/0167-4781(95)00130-9

Bai, M. Y., Fan, M., Oh, E., and Wang, Z. Y. (2012). A triple helix-loophelix/basic helix-loop-helix cascade controls cell elongation downstream of multiple hormonal and environmental signaling pathways in Arabidopsis. Plant cell 24, 4917-4929. doi: 10.1105/tpc.112.105163

Bankel, L., Lindstedt, G., and Lindstedt, S. (1972). Thymidine 2 '-hydroxylation in Neurospora crassa. J. Biol. Chem. 247, 6128-6134.

Brady, S. M., Sarkar, S. F., Bonetta, D., and McCourt, P. (2003). The ABSCISIC ACID INSENSITIVE 3 (ABI3) gene is modulated by farnesylation and is involved in auxin signaling and lateral root development in Arabidopsis. Plant J. 34, 67-75. doi: 10.1046/j.1365-313X.2003.01707.x

Brisson, L., El Bakkali-Taheri, N., Giorgi, M., Fadel, A., Kaizer, J., Reglier, M., et al. (2012). 1-Aminocyclopropane-1-carboxylic acid oxidase: insight into cofactor binding from experimental and theoretical studies. J. Biol. Inorg. Chem. 17, 939-949. doi: 10.1007/s00775-012-0910-3

Britsch, L. (1990). Purification and characterization of flavone synthase I, a 2oxoglutarate-dependent desaturase. Arch. Biochem. Biophys. 282, 152-160. doi: 10.1016/0003-9861(90)90099-K

Britsch, L., and Grisebach, H. (1986). Purification and characterization of (2S)flavanone 3-hydroxylase from Petunia hybrida. Eur. J. Biochem. 156, 569-577. doi: 10.1111/j.1432-1033.1986.tb09616.x

Cantoro, R., Crocco, C. D., Benech-Arnold, R. L., and Rodriguez, M. V. (2013). In vitro binding of Sorghum bicolor transcription factors $\mathrm{ABI} 4$ and $\mathrm{ABI} 5$ to a conserved region of a GA 2-OXIDASE promoter: possible role of this interaction in the expression of seed dormancy. J. Exp. Bot. 64, 5721-5735. doi: $10.1093 / \mathrm{jxb} / \mathrm{ert} 347$

Carpita, N. C., and Kanabus, J. (1988). Chemical structure of the cell walls of dwarf maize and changes mediated by gibberellin. Plant Physiol. 88, 671-678. doi: 10.1104/pp.88.3.671

Cho, H. T., and Cosgrove, D. J. (2002). Regulation of root hair initiation and expansin gene expression in Arabidopsis. Plant Cell 14, 3237-3253. doi: $10.1105 /$ tpc.006437

Chrispeels, M. J. (1984). Prolyl hydroxylase in plants. Methods Enzymol. 107, 361-369. doi: 10.1016/0076-6879(84)07024-5

Clifton, I. J., Doan, L. X., Sleeman, M. C., Topf, M., Suzuki, H., Wilmouth, R. C., et al. (2003). Crystal structure of carbapenem synthase (CarC). J. Biol. Chem. 278, 20843-20850. doi: 10.1074/jbc.M213054200

Clifton, I. J., McDonough, M. A., Ehrismann, D., Kershaw, N. J., Granatino, N., and Schofield, C. J. (2006). Structural studies on 2-oxoglutarate oxygenases and related double-stranded beta-helix fold proteins. J. Inorg. Biochem. 100, 644-669. doi: 10.1016/j.jinorgbio.2006.01.024

Cui, D., Neill, S. J., Tang, Z., and Cai, W. (2005). Gibberellin-regulated XET is differentially induced by auxin in rice leaf sheath bases during gravitropic bending. J. Exp. Bot. 56, 1327-1334. doi: 10.1093/jxb/eri133

Cutler, S., Ghassemian, M., Bonetta, D., Cooney, S., and McCourt, P. (1996). A protein farnesyl transferase involved in abscisic acid signal transduction in Arabidopsis. Science 273, 1239-1241. doi: 10.1126/science.273.5279.1239

De Carolis, E., and De Luca, V. (1993). Purification, characterization, and kinetic analysis of a 2-oxoglutarate-dependent dioxygenase involved in vindoline biosynthesis from Catharanthus roseus. J. Biol. Chem. 268, 5504-5511.

De Jong, L., and Kemp, A. (1984). Stoicheiometry and kinetics of the prolyl 4-hydroxylase partial reaction. Biochim. Biophys. Acta 787, 105-111. doi: 10.1016/0167-4838(84)90113-4

DiDonato, R. J. Jr., Roberts, L. A., Sanderson, T., Eisley, R. B., and Walker, E. L. (2004). Arabidopsis Yellow Stripe-Like2 (YSL2): a metal-regulated gene encoding a plasma membrane transporter of nicotianamine-metal complexes. Plant J. 39, 403-414. doi: 10.1111/j.1365-313X.2004.02128.x

Dotzlaf, J. E., and Yeh, W. K. (1987). Copurification and characterization of deacetoxycephalosporin C synthetase/hydroxylase from Cephalosporium acremonium. J. Bacteriol. 169, 1611-1618.
Dotzlaf, J. E., and Yeh, W. K. (1989). Purification and properties of deacetoxycephalosporin $\mathrm{C}$ synthase from recombinant Escherichia coli and its comparison with the native enzyme purified from Streptomyces clavuligerus. J. Biol. Chem. 264, 10219-10227.

Elkins, J. M., Hewitson, K. S., McNeill, L. A., Seibel, J. F., Schlemminger, I., Pugh, C. W., et al. (2003). Structure of factor-inhibiting hypoxia-inducible factor (HIF) reveals mechanism of oxidative modification of HIF-1 alpha. J. Biol. Chem. 278, 1802-1806. doi: 10.1074/jbc.C200644200

Elkins, J. M., Ryle, M. J., Clifton, I. J., Dunning Hotopp, J. C., Lloyd, J. S., Burzlaff, N. I., et al. (2002). X-ray crystal structure of Escherichia coli taurine/alpha-ketoglutarate dioxygenase complexed to ferrous iron and substrates. Biochemistry 41, 5185-5192. doi: 10.1021/bi016014e

Eriksson, M., Myllyharju, J., Tu, H., Hellman, M., and Kivirikko, K. I. (1999). Evidence for 4-hydroxyproline in viral proteins. Characterization of a viral prolyl 4-hydroxylase and its peptide substrates. J. Biol. Chem. 274, 22131-22134. doi: 10.1074/jbc.274.32.22131

Finkelstein, R., Lynch, T., Reeves, W., Petitfils, M., and Mostachetti, M. (2011). Accumulation of the transcription factor ABA-insensitive (ABI) 4 is tightly regulated post-transcriptionally. J. Exp. Bot. 62, 3971-3979. doi: 10.1093/jxb/err093

Finkelstein, R. R., Wang, M. L., Lynch, T. J., Rao, S., and Goodman, H. M. (1998). The Arabidopsis abscisic acid response locus ABI4 encodes an APETALA 2 domain protein. Plant Cell 10, 1043-1054. doi: 10.1105/tpc.10.6.1043

Flagg, S. C., Martin, C. B., Taabazuing, C. Y., Holmes, B. E., and Knapp, M. J. (2012). Screening chelating inhibitors of HIF-prolyl hydroxylase domain 2 (PHD2) and factor inhibiting HIF (FIH). J. Inorg. Biochem. 113, 25-30. doi: 10.1016/j.jinorgbio.2012.03.002

Fourcroy, P., Siso-Terraza, P., Sudre, D., Saviron, M., Reyt, G., Gaymard, F., et al. (2014). Involvement of the ABCG37 transporter in secretion of scopoletin and derivatives by Arabidopsis roots in response to iron deficiency. New Phytol. 201, 155-167. doi: 10.1111/nph.12471

Gille, C., and Frommel, C. (2001). STRAP: editor for STRuctural alignments of proteins. Bioinformatics 17, 377-378. doi: 10.1093/bioinformatics/17.4.377

Gillespie, D. T. (2007). Stochastic simulation of chemical kinetics. Annu. Rev. Phys. Chem. 58, 35-55. doi: 10.1146/annurev.physchem.58.032806.104637

Gronke, R. S., Welsch, D. J., VanDusen, W. J., Garsky, V. M., Sardana, M. K., Stern, A. M., et al. (1990). Partial purification and characterization of bovine liver aspartyl beta-hydroxylase. J. Biol. Chem. 265, 8558-8565.

Guex, N., and Peitsch, M. C. (1997). SWISS-MODEL and the Swiss-PdbViewer: an environment for comparative protein modeling. Electrophoresis 18, 2714-2723. doi: 10.1002/elps.1150181505

Gunzler, V., Hanauske-Abel, H. M., Myllyla, R., Mohr, J., and Kivirikko, K. I. (1987). Time-dependent inactivation of chick-embryo prolyl 4-hydroxylase by coumalic acid. Evidence for a syncatalytic mechanism. Biochem. J. 242, 163-169.

Hagel, J. M., and Facchini, P. J. (2010a). Biochemistry and occurrence of o-demethylation in plant metabolism. Front. Physiol. 1:14. doi: 10.3389/fphys.2010.00014

Hagel, J. M., and Facchini, P. J. (2010b). Dioxygenases catalyze the Odemethylation steps of morphine biosynthesis in opium poppy. Nat. Chem. Biol. 6, 273-275. doi: 10.1038/nchembio.317

Hasenauer, J., Wolf, V., Kazeroonian, A., and Theis, F. J. (2014). Method of conditional moments (MCM) for the Chemical Master Equation: a unified framework for the method of moments and hybrid stochastic-deterministic models. J. Math. Biol. 69, 687-735. doi: 10.1007/s00285-013-0711-5

Hashimoto, T., and Yamada, Y. (1986). Hyoscyamine 6beta-hydroxylase, a 2oxoglutarate-dependent dioxygenase, in alkaloid-producing root cultures. Plant Physiol. 81, 619-625. doi: 10.1104/pp.81.2.619

Hashimoto, T., and Yamada, Y. (1987). Purification and characterization of hyoscyamine 6 beta-hydroxylase from root cultures of Hyoscyamus niger L. Hydroxylase and epoxidase activities in the enzyme preparation. Eur. J. Biochem. 164, 277-285. doi: 10.1111/j.1432-1033.1987.tb11055.x

Hausinger, R. P. (2004). FeII/alpha-ketoglutarate-dependent hydroxylases and related enzymes. Crit. Rev. Biochem. Mol. Biol. 39, 21-68. doi: $10.1080 / 10409230490440541$

Hedden, P., and Phillips, A. L. (2000a). Manipulation of hormone biosynthetic genes in transgenic plants. Curr. Opin. Biotechnol. 11, 130-137. doi: 10.1016/S0958-1669(00)00071-9 
Hedden, P., and Phillips, A. L. (2000b). Gibberellin metabolism: new insights revealed by the genes. Trends Plant Sci. 5, 523-530. doi: 10.1016/S13601385(00)01790-8

Helaakoski, T., Annunen, P., Vuori, K., MacNeil, I. A., Pihlajaniemi, T., and Kivirikko, K. I. (1995). Cloning, baculovirus expression, and characterization of a second mouse prolyl 4-hydroxylase alpha-subunit isoform: formation of an alpha 2 beta 2 tetramer with the protein disulfide-isomerase/beta subunit. Proc. Natl. Acad. Sci. U.S.A. 92, 4427-4431. doi: 10.1073/pnas.92.10.4427

Hewitson, K. S., McNeill, L. A., Riordan, M. V., Tian, Y. M., Bullock, A. N., Welford, R. W., et al. (2002). Hypoxia-inducible factor (HIF) asparagine hydroxylase is identical to factor inhibiting HIF (FIH) and is related to the cupin structural family. J. Biol. Chem. 277, 26351-26355. doi: 10.1074/jbc.C200273200

Hijazi, M., Roujol, D., Nguyen-Kim, H., Del Rocio Cisneros Castillo, L., Saland, E., Jamet, E., et al. (2014). Arabinogalactan protein 31 (AGP31), a putative network-forming protein in Arabidopsis thaliana cell walls? Ann. Bot. 114, 1087-1097. doi: 10.1093/aob/mcu038

Hutton, J. J., Tappel, A. L., and Undenfried, S. (1967). Cofactor and substrate requirements of collagen proline hydroxylase. Arch. Biochem. Biophys. 118, 231-240. doi: 10.1016/0003-9861(67)90302-5

Hyry, M., Lantto, J., and Myllyharju, J. (2009). Missense mutations that cause Bruck syndrome affect enzymatic activity, folding, and oligomerization of lysyl hydroxylase 2. J. Biol. Chem. 284, 30917-30924. doi: 10.1074/jbc.M109.021238

Ishimaru, Y., Suzuki, M., Tsukamoto, T., Suzuki, K., Nakazono, M., Kobayashi, T., et al. (2006). Rice plants take up iron as an $\mathrm{Fe}^{3+}$-phytosiderophore and as $\mathrm{Fe}^{2+}$. Plant J. 45, 335-346. doi: 10.1111/j.1365-313X.2005.02624.x

Itai, R. N., Ogo, Y., Kobayashi, T., Nakanishi, H., and Nishizawa, N. K. (2013). Rice genes involved in phytosiderophore biosynthesis are synchronously regulated during the early stages of iron deficiency in roots. Rice 6, 16. doi: 10.1186/19398433-6-16

Janc, J. W., Egan, L. A., and Townsend, C. A. (1995). Purification and characterization of clavaminate synthase from Streptomyces antibioticus. A multifunctional enzyme of clavam biosynthesis. J. Biol. Chem. 270, 5399-5404. doi: $10.1074 /$ jbc.270.10.5399

Jansen, G. A., Mihalik, S. J., Watkins, P. A., Jakobs, C., Moser, H. W., and Wanders, R. J. (1998). Characterization of phytanoyl-Coenzyme A hydroxylase in human liver and activity measurements in patients with peroxisomal disorders. Clin. Chim. Acta 271, 203-211. doi: 10.1016/S0009-8981(97)00259-3

Kai, K., Mizutani, M., Kawamura, N., Yamamoto, R., Tamai, M., Yamaguchi, H., et al. (2008).. Scopoletin is biosynthesized via ortho-hydroxylation of feruloyl CoA by a 2-oxoglutarate-dependent dioxygenase in Arabidopsis thaliana. Plant J. 55, 989-999. doi: 10.1111/j.1365-313X.2008.03568.x

Kaska, D. D., Gunzler, V., Kivirikko, K. I., and Myllyla, R. (1987). Characterization of a low-relative-molecular-mass prolyl 4-hydroxylase from the green alga Chlamydomonas reinhardii. Biochem. J. 241, 483-490.

Kaska, D. D., Myllyla, R., Gunzler, V., Gibor, A., and Kivirikko, K. I. (1988). Prolyl 4-hydroxylase from Volvox carteri. A low-Mr enzyme antigenically related to the alpha subunit of the vertebrate enzyme. Biochem. J. 256, 257-263.

Kato, N., Suzuki, H., Takagi, H., Uramoto, M., Takahashi, S., and Osada, H. (2011). Gene disruption and biochemical characterization of verruculogen synthase of Aspergillus fumigatus. Chembiochem 12, 711-714. doi: 10.1002/cbic.201000562

Kawai, Y., Ono, E., and Mizutani, M. (2014). Evolution and diversity of the 2-oxoglutarate-dependent dioxygenase superfamily in plants. Plant J. 78, 328-343. doi: $10.1111 /$ tpj.12479

Kobayashi, T., Itai, R. N., Aung, M. S., Senoura, T., Nakanishi, H., and Nishizawa, N. K. (2012). The rice transcription factor IDEF1 directly binds to iron and other divalent metals for sensing cellular iron status. Plant J. 69, 81-91. doi: 10.1111/j.1365-313X.2011.04772.x

Kobayashi, T., Nakanishi, H., and Nishizawa, N. K. (2010). Recent insights into iron homeostasis and their application in graminaceous crops. Proc. Jpn. Acad. Ser. B. Phys. Biol. Sci. 86, 900-913. doi: 10.2183/pjab.86.900

Kobayashi, T., and Nishizawa, N. K. (2012). Iron uptake, translocation, and regulation in higher plants. Annu. Rev. Plant Biol. 63, 131-152. doi: 10.1146/annurev-arplant-042811-105522

Kobayashi, T., Ogo, Y., Itai, R. N., Nakanishi, H., Takahashi, M., Mori, S., et al. (2007). The transcription factor IDEF1 regulates the response to and tolerance of iron deficiency in plants. Proc. Natl. Acad. Sci. U.S.A. 104, 19150-19155. doi: 10.1073/pnas.0707010104
Koike, S., Inoue, H., Mizuno, D., Takahashi, M., Nakanishi, H., Mori, S., et al. (2004). OsYSL2 is a rice metal-nicotianamine transporter that is regulated by iron and expressed in the phloem. Plant J. 39, 415-424. doi: 10.1111/j.1365313X.2004.02146.x

Koivunen, P., Hirsila, M., Gunzler, V., Kivirikko, K. I., and Myllyharju, J. (2004). Catalytic properties of the asparaginyl hydroxylase (FIH) in the oxygen sensing pathway are distinct from those of its prolyl 4-hydroxylases. J. Biol. Chem. 279, 9899-9904. doi: 10.1074/jbc.M312254200

Kondo, A., Blanchard, J. S., and Englard, S. (1981). Purification and properties of calf liver gamma-butyrobetaine hydroxylase. Arch. Biochem. Biophys. 212, 338-346. doi: 10.1016/0003-9861(81)90374-X

Koornneef, M., Reuling, G., and Karssen, C. M. (1984). The isolation and characterization of abscisic acid-insensitive mutants of Arabidopsis thaliana. Physiol. Plant. 61, 377-383. doi: 10.1111/j.1399-3054.1984.tb06343.x

Kukkola, L., Hieta, R., Kivirikko, K. I., and Myllyharju, J. (2003). Identification and characterization of a third human, rat, and mouse collagen prolyl 4-hydroxylase isoenzyme. J. Biol. Chem. 278, 47685-47693. doi: 10.1074/jbc.M306806200

Kukkola, L., Koivunen, P., Pakkanen, O., Page, A. P., and Myllyharju, J. (2004). Collagen prolyl 4-hydroxylase tetramers and dimers show identical decreases in $\mathrm{Km}$ values for peptide substrates with increasing chain length: mutation of one of the two catalytic sites in the tetramer inactivates the enzyme by more than half. J. Biol. Chem. 279, 18656-18661. doi: 10.1074/jbc.M401 514200

Kumar, S., and Pandey, A. K. (2013). Chemistry and biological activities of flavonoids: an overview. ScientificWorldJournal 2013:162750. doi: $10.1155 / 2013 / 162750$

Kundu, S. (2012). Distribution and prediction of catalytic domains in 2-oxoglutarate dependent dioxygenases. BMC Res. Notes 5:410. doi: 10.1186/1756-0500-5-410

Kundu, S. (2015). Unity in diversity, a systems approach to regulating plant cell physiology by 2-oxoglutarate-dependent dioxygenases. Front. Plant Sci. 6:98 doi: $10.3389 /$ fpls.2015.00098

Kwak, S. S., Kamiya, Y., Sakurai, A., Takahashi, N., and Graebe, J. (1988). Partial purification and characterization of gibberellins 3beta-hydroxylase from immature seeds of Phaseolus vulgaris. Plant Cell Physiol. 29, 935-943.

Lawrence, C. C., Sobey, W. J., Field, R. A., Baldwin, J. E., and Schofield, C. J. (1996). Purification and initial characterization of proline 4-hydroxylase from Streptomyces griseovirdis P8648: a 2-oxoacid, ferrous-dependent dioxygenase involved in etamycin biosynthesis. Biochem. J. 313, 185-191.

Leung, J., Merlot, S., and Giraudat, J. (1997). The Arabidopsis ABSCISIC ACID-INSENSITIVE2 (ABI2) and ABI1 genes encode homologous protein phosphatases 2C involved in abscisic acid signal transduction. Plant Cell 9, 759-771. doi: 10.1105/tpc.9.5.759

Liras, P., and Demain, A. L. (2009). Chapter 16. Enzymology of beta-lactam compounds with cephem structure produced by actinomycete. Methods Enzymol. 458, 401-429. doi: 10.1016/S0076-6879(09)04816-2

Long, S. P., Lu, Y., Wang, Y. X., Yang, C. X., Lan, X. Z., and Liao, Z. H. (2013). [Enhancement of tropane alkaloids production in transgenic hair roots of Atropa belladonna by overexpressing endogenous genes AbPMT and AbH6H]. Yao Xue Xue Bao 48, 243-249.

Lukacin, R., Groning, I., Pieper, U., and Matern, U. (2000). Site-directed mutagenesis of the active site serine 290 in flavanone 3beta-hydroxylase from Petunia hybrida. Eur. J. Biochem. 267, 853-860. doi: 10.1046/j.14321327.2000.01064.x

Luo, L., Pappalardi, M. B., Tummino, P. J., Copeland, R. A., Fraser, M. E., Grzyska, P. K., et al. (2006). An assay for $\mathrm{Fe}(\mathrm{II}) / 2$-oxoglutarate-dependent dioxygenases by enzyme-coupled detection of succinate formation. Anal. Biochem. 353, 69-74. doi: 10.1016/j.ab.2006.03.033

Ma, J. F., Shinada, T., Matsuda, C., and Nomoto, K. (1995). Biosynthesis of phytosiderophores, mugineic acids, associated with methionine cycling. J. Biol. Chem. 270, 16549-16554. doi: 10.1074/jbc.270.28.16549

Magome, H., Yamaguchi, S., Hanada, A., Kamiya, Y., and Oda, K. (2008). The DDF1 transcriptional activator upregulates expression of a gibberellindeactivating gene, GA2ox7, under high-salinity stress in Arabidopsis. Plant J. 56, 613-626. doi: 10.1111/j.1365-313X.2008.03627.x

Matsuda, J., Okabe, S., Hashimoto, T., and Yamada, Y. (1991). Molecular cloning of hyoscyamine 6 beta-hydroxylase, a 2-oxoglutarate-dependent dioxygenase, from cultured roots of Hyoscyamus niger. J. Biol. Chem. 266, 9460-9464. 
McGinnis, K., Ku, G. M., VanDusen, W. J., Fu, J., Garsky, V., Stern, A. M., et al. (1996). Site-directed mutagenesis of residues in a conserved region of bovine aspartyl (asparaginyl) beta-hydroxylase: evidence that histidine 675 has a role in binding $\mathrm{Fe}^{2+}$. Biochemistry 35, 3957-3962. doi: 10.1021/bi951520n

Mirica, L. M., and Klinman, J. P. (2008). The nature of $\mathrm{O}_{2}$ activation by the ethylene-forming enzyme 1-aminocyclopropane-1-carboxylic acid oxidase. Proc. Natl. Acad. Sci. U.S.A. 105, 1814-1819. doi: 10.1073/pnas.0711626105

Mori, H., Shibasaki, T., Yano, K., and Ozaki, A. (1997). Purification and cloning of a proline 3-hydroxylase, a novel enzyme which hydroxylates free L-proline to cis-3-hydroxy-L-proline. J. Bacteriol. 179, 5677-5683.

Muller, I., Kahnert, A., Pape, T., Sheldrick, G. M., Meyer-Klaucke, W., Dierks, T., et al. (2004). Crystal structure of the alkylsulfatase AtsK: insights into the catalytic mechanism of the $\mathrm{Fe}$ (II) alpha-ketoglutarate-dependent dioxygenase superfamily. Biochemistry 43, 3075-3088. doi: 10.1021/bi035752v

Muller, K., Linkies, A., Vreeburg, R. A., Fry, S. C., Krieger-Liszkay, A., and Leubner-Metzger, G. (2009). In vivo cell wall loosening by hydroxyl radicals during cress seed germination and elongation growth. Plant Physiol. 150, 1855-1865. doi: 10.1104/pp.109.139204

Muller, T. A., Fleischmann, T., van der Meer, J. R., and Kohler, H. P. (2006). Purification and characterization of two enantioselective alpha-ketoglutaratedependent dioxygenases, RdpA and SdpA, from Sphingomonas herbicidovorans MH. Appl. Environ. Microbiol. 72, 4853-4861. doi: 10.1128/AEM.02758-05

Munsky, B., and Khammash, M. (2006). The finite state projection algorithm for the solution of the chemical master equation. J. Chem. Phys. 124, 044104. doi: $10.1063 / 1.2145882$

Myllyharju, J. (2003). Prolyl 4-hydroxylases, the key enzymes of collagen biosynthesis. Matrix Biol. 22, 15-24. doi: 10.1016/S0945-053X(03)00006-4

Myllyharju, J. (2008). Prolyl 4-hydroxylases, key enzymes in the synthesis of collagens and regulation of the response to hypoxia, and their roles as treatment targets. Ann. Med. 40, 402-417. doi: 10.1080/07853890801986594

Nagahama, K., Ogawa, T., Fujii, T., Tazaki, M., Tanase, S., Morino, Y., et al. (1991). Purification and properties of an ethylene-forming enzyme from Pseudomonas syringae pv. phaseolicola PK2. J. Gen. Microbiol. 137, 2281-2286. doi: 10.1099/00221287-137-10-2281

Nagahama, K., Yoshino, K., Matsuoka, M., Tanase, S., Ogawa, T., and Fukuda, H. (1998). Site-directed mutagenesis of histidine residues in the ethylene-forming enzyme from Pseudomonas syringae. J. Ferment. Bioeng. 85, 255-258. doi: 10.1016/S0922-338X(97)85671-1

Nakanishi, H., Yamaguchi, H., Sasakuma, T., Nishizawa, N. K., and Mori, S. (2000). Two dioxygenase genes, Ids3 and Ids2, from Hordeum vulgare are involved in the biosynthesis of mugineic acid family phytosiderophores. Plant Mol. Biol. 44, 199-207. doi: 10.1023/A:1006491521586

Nietfeld, J. J., and Kemp, A. (1980). Properties of prolyl 4-hydroxylase containing firmly-bound iron. Biochim. Biophys. Acta 613, 349-358. doi: 10.1016/00052744(80)90089-3

Nozoye, T., Nagasaka, S., Kobayashi, T., Takahashi, M., Sato, Y., Sato, Y., et al. (2011). Phytosiderophore efflux transporters are crucial for iron acquisition in graminaceous plants. J. Biol. Chem. 286, 5446-5454. doi: 10.1074/jbc.M110.180026

Ogo, Y., Itai, R. N., Nakanishi, H., Kobayashi, T., Takahashi, M., Mori, S., et al. (2007). The rice bHLH protein OsIRO2 is an essential regulator of the genes involved in Fe uptake under Fe-deficient conditions. Plant J. 51, 366-377. doi: 10.1111/j.1365-313X.2007.03149.x

Park, S. H., Nakajima, M., Hasegawa, M., and Yamaguchi, I. (2005). Similarities and differences between the characteristics of gibberellin-binding protein and gibberellin 2-oxidases in adzuki bean (Vigna angularis) seedlings. Biosci. Biotechnol. Biochem. 69, 1508-1514. doi: 10.1271/bbb.69.1508

Passoja, K., Rautavuoma, K., Ala-Kokko, L., Kosonen, T., and Kivirikko, K. I. (1998). Cloning and characterization of a third human lysyl hydroxylase isoform. Proc. Natl. Acad. Sci. U.S.A. 95, 10482-10486. doi: 10.1073/pnas.95.18.10482

Pramod, K. K., Singh, S., and Jayabaskaran, C. (2010). Biochemical and structural characterization of recombinant hyoscyamine 6beta-hydroxylase from Datura metel L. Plant Physiol. Biochem. 48, 966-970. doi: 10.1016/j.plaphy.2010. 09.003

Price, J. C., Barr, E. W., Glass, T. E., Krebs, C., and Bollinger, J. M. Jr. (2003b). Evidence for hydrogen abstraction from $\mathrm{C} 1$ of taurine by the high-spin
$\mathrm{Fe}(\mathrm{IV})$ intermediate detected during oxygen activation by taurine:alphaketoglutarate dioxygenase (TauD). J. Am. Chem. Soc. 125, 13008-13009. doi: $10.1021 / \mathrm{ja} 037400 \mathrm{~h}$

Price, J. C., Barr, E. W., Tirupati, B., Bollinger, J. M. Jr., and Krebs, C. (2003a). The first direct characterization of a high-valent iron intermediate in the reaction of an alpha-ketoglutarate-dependent dioxygenase: a high-spin FeIV complex in taurine/alpha-ketoglutarate dioxygenase (TauD) from Escherichia coli. Biochemistry 42, 7497-7508. doi: 10.1021/bi030011f

Puistola, U. (1982). Catalytic properties of lysyl hydroxylase from cells synthesizing genetically different collagen types. Biochem. J. 201, 215-219.

Puistola, U., Turpeenniemi-Hujanen, T. M., Myllyla, R., and Kivirikko, K. I. (1980). Studies on the lysyl hydroxylase reaction. I. Initial velocity kinetics and related aspects. Biochim. Biophys. Acta 61 1, 40-50. doi: 10.1016/0005-2744(80)90040-6

Rautavuoma, K., Takaluoma, K., Passoja, K., Pirskanen, A., Kvist, A. P., Kivirikko, K. I., et al. (2002). Characterization of three fragments that constitute the monomers of the human lysyl hydroxylase isoenzymes $1-3$. The $30-\mathrm{kDa} \mathrm{N}-$ terminal fragment is not required for lysyl hydroxylase activity. J. Biol. Chem. 277, 23084-23091. doi: 10.1074/jbc.M112077200

Rocklin, A. M., Kato, K., Liu, H. W., Que, L. Jr., and Lipscomb, J. D. (2004). Mechanistic studies of 1-aminocyclopropane-1-carboxylic acid oxidase: single turnover reaction. J. Biol. Inorg. Chem. 9, 171-182. doi: 10.1007/s00775-0030510-3

Rodriguez-Celma, J., Lin, W. D., Fu, G. M., Abadia, J., Lopez-Millan, A. F., and Schmidt, W. (2013). Mutually exclusive alterations in secondary metabolism are critical for the uptake of insoluble iron compounds by Arabidopsis and Medicago truncatula. Plant Physiol. 162, 1473-1485. doi: 10.1104/pp.113.220426

Saito, K., Kobayashi, M., Gong, Z., Tanaka, Y., and Yamazaki, M. (1999). Direct evidence for anthocyanidin synthase as a 2-oxoglutarate-dependent oxygenase: molecular cloning and functional expression of cDNA from a red forma of Perilla frutescens. Plant J.17, 181-189. doi: 10.1046/j.1365-313X.1999.00365.x

Salowe, S. P., Marsh, E. N., and Townsend, C. A. (1990). Purification and characterization of clavaminate synthase from Streptomyces clavuligerus: an unusual oxidative enzyme in natural product biosynthesis. Biochemistry 29, 6499-6508. doi: 10.1021/bi00479a023

Schikora, A., and Schmidt, W. (2001a). Iron stress-induced changes in root epidermal cell fate are regulated independently from physiological responses to low iron availability. Plant Physiol. 125, 1679-1687. doi: 10.1104/pp.125. 4.1679

Schikora, A., and Schmidt, W. (2001b). Acclimative changes in root epidermal cell fate in response to Fe and P deficiency: a specific role for auxin? Protoplasma 218, 67-75. doi: 10.1007/BF01288362

Schmid, N. B., Giehl, R. F., Doll, S., Mock, H. P., Strehmel, N., Scheel, D., et al. (2014). Feruloyl-CoA 6'-Hydroxylase1-dependent coumarins mediate iron acquisition from alkaline substrates in Arabidopsis. Plant Physiol. 164, 160-172. doi: 10.1104/pp.113.228544

Schnoerr, D., Sanguinetti, G., and Grima, R. (2014). The complex chemical Langevin equation. J. Chem. Phys. 141, 024103. doi: 10.1063/1.4885345

Schomburg, I., Chang, A., and Schomburg, D. (2002). BRENDA, enzyme data and metabolic information. Nucleic Acids Res. 30, 47-49. doi: 10.1093/nar/30.1.47

Smith, V. A., and MacMillan, J. (1984). Purification and partial characterization of a gibberellin 2beta-hydroxylase from Phaseolus vulgaris. J. Plant Growth Regul. 2, 251-264. doi: 10.1007/BF02042254

Swiegers, J. H., Vaz, F. M., Pretorius, I. S., Wanders, R. J., and Bauer, F. F. (2002). Carnitine biosynthesis in Neurospora crassa: identification of a cDNA coding for epsilon-N-trimethyllysine hydroxylase and its functional expression in Saccharomyces cerevisiae. FEMS Microbiol. Lett. 210, 19-23. doi: 10.1016/s03781097(02)00520-7

Tanaka, M., Shibata, H., and Uchida, T. (1980). A new prolyl hydroxylase acting on poly-L-proline, from suspension cultured cells of Vinca rosea. Biochim. Biophys. Acta 616, 188-198. doi: 10.1016/0005-2744(80)90137-0

Tezuka, K., Taji, T., Hayashi, T., and Sakata, Y. (2013). A novel abi5 allele reveals the importance of the conserved Ala in the $\mathrm{C} 3$ domain for regulation of downstream genes and salt tolerance during germination in Arabidopsis. Plant Signal. Behav. 8:e23455. doi: 10.4161/psb.23455

Thinnes, C. C., England, K. S., Kawamura, A., Chowdhury, R., Schofield, C. J., and Hopkinson, R. J. (2014). Targeting histone lysine demethylases - Progress, 
challenges, and the future. Biochim. Biophys. Acta 1839, 1416-1432. doi: 10.1016/j.bbagrm.2014.05.009

Thornburg, L. D., Lai, M. T., Wishnok, J. S., and Stubbe, J. (1993). A non-heme iron protein with heme tendencies: an investigation of the substrate specificity of thymine hydroxylase. Biochemistry 32, 14023-14033. doi: 10.1021/bi0021 $3 \mathrm{a} 036$

Tryggvason, K., Majamaa, K., Risteli, J., and Kivirikko, K. I. (1979). Partial purification and characterization of chick-embryo prolyl 3-hydroxylase. Biochem. J. 183, 303-307.

Tuderman, L., Myllyla, R., and Kivirikko, K. I. (1977). Mechanism of the prolyl hydroxylase reaction. 1. Role of co-substrates. Eur. J. Biochem. 80, 341-348. doi: 10.1111/j.1432-1033.1977.tb11888.x

Urzica, E. I., Casero, D., Yamasaki, H., Hsieh, S. I., Adler, L. N., Karpowicz, S. J., et al. (2012). Systems and trans-system level analysis identifies conserved iron deficiency responses in the plant lineage. Plant Cell 24, 3921-3948. doi: $10.1105 /$ tpc.112.102491

Vainio, S., Genest, P. A., ter Riet, B., van Luenen, H., and Borst, P. (2009). Evidence that J-binding protein 2 is a thymidine hydroxylase catalyzing the first step in the biosynthesis of DNA base J. Mol. Biochem. Parasitol. 164, 157-161. doi: 10.1016/j.molbiopara.2008.12.001

Valegard, K., Terwisscha van Scheltinga, A. C., Dubus, A., Ranghino, G., Oster, L. M., Hajdu, J., et al. (2004). The structural basis of cephalosporin formation in a mononuclear ferrous enzyme. Nat. Struct. Mol. Biol. 11, 95-101. doi: $10.1038 /$ nsmb712

Vaz, F. M., Ofman, R., Westinga, K., Back, J. W., and Wanders, R. J. (2001). Molecular and Biochemical characterization of rat epsilon - $\mathrm{N}$-trimethyllysine hydroxylase, the first enzyme of carnitine biosynthesis. J. Biol. Chem. 276, 33512-33517. doi: 10.1074/jbc.M105929200

Vazquez-Flota, F., De Carolis, E., Alarco, A. M., and De Luca, V. (1997). Molecular cloning and characterization of desacetoxyvindoline-4-hydroxylase, a 2-oxoglutarate dependent-dioxygenase involved in the biosynthesis of vindoline in Catharanthus roseus (L.) G. Don. Plant Mol. Biol. 34, 935-948. doi: 10.1023/A:1005894001516

Veijola, J., Koivunen, P., Annunen, P., Pihlajaniemi, T., and Kivirikko, K. I. (1994). Cloning, baculovirus expression, and characterization of the alpha subunit of prolyl 4-hydroxylase from the nematode Caenorhabditis elegans. This alpha subunit forms an active alpha beta dimer with the human protein disulfide isomerase/beta subunit. J. Biol. Chem. 269, 26746-26753.

Wang, Q. P., VanDusen, W. J., Petroski, C. J., Garsky, V. M., Stern, A. M., and Friedman, P. A. (1991). Bovine liver aspartyl beta-hydroxylase. Purification and characterization. J. Biol. Chem. 266, 14004-14010.

Wehner, K. A., Schutz, S., and Sarnow, P. (2010). OGFOD1, a novel modulator of eukaryotic translation initiation factor 2alpha phosphorylation and the cellular response to stress. Mol. Cell. Biol. 30, 2006-2016. doi: 10.1128/MCB.01350-09
Wellmann, F., Lukacin, R., Moriguchi, T., Britsch, L., Schiltz, E., and Matern, U. (2002). Functional expression and mutational analysis of flavonol synthase from Citrus unshiu. Eur. J. Biochem. 269, 4134-4142. doi: 10.1046/j.14321033.2002.03108.x

Wilmouth, R. C., Turnbull, J. J., Welford, R. W., Clifton, I. J., Prescott, A. G., and Schofield, C. J. (2002). Structure and mechanism of anthocyanidin synthase from Arabidopsis thaliana. Structure 10, 93-103. doi: 10.1016/S09692126(01)00695-5

Wolf, V., Goel, R., Mateescu, M., and Henzinger, T. A. (2010). Solving the chemical master equation using sliding windows. BMC Syst. Biol. 4:42. doi: 10.1186/1752-0509-4-42

Yu, Z., Genest, P. A., ter, Riet, B., Sweeney, K., DiPaolo, C., Kieft, R., et al. (2007). The protein that binds to DNA base $J$ in trypanosomatids has features of a thymidine hydroxylase. Nucleic Acids Res. 35, 2107-2115. doi: 10.1093/nar/gkm049

Zawaski, C., and Busov, V. B. (2014). Roles of gibberellin catabolism and signaling in growth and physiological response to drought and short-day photoperiods in Populus trees. PLoS ONE 9:e86217. doi: 10.1371/journal.pone.0086217

Zentella, R., Zhang, Z. L., Park, M., Thomas, S. G., Endo, A., Murase, K., et al. (2007). Global analysis of della direct targets in early gibberellin signaling in Arabidopsis. Plant Cell 19, 3037-3057. doi: 10.1105/tpc.107.054999

Zhang, X. Q., Luo, Z. W., Zhang, H., Wang, F. Y., Sun, J. W., and Sun, M. (2012). [Scopolamine and hyoscyamine synthesis in hair roots culture of Datura metel] Zhongguo Zhong Yao Za Zhi 37, 3223-3228.

Zhang, Z., Ren, J. S., Clifton, I. J., and Schofield, C. J. (2004). Crystal structure and mechanistic implications of 1-aminocyclopropane-1-carboxylic acid oxidase-the ethylene-forming enzyme. Chem. Biol. 11, 1383-1394. doi: 10.1016/j.chembiol.2004.08.012

Zhang, Z., Ren, J., Stammers, D. K., Baldwin, J. E., Harlos, K., and Schofield, C. J. (2000). Structural origins of the selectivity of the trifunctional oxygenase clavaminic acid synthase. Nat. Struct. Biol. 7, 127-133. doi: 10.1038/72398

Conflict of Interest Statement: The work presented here has not been funded by any agency, has been done during the personal time of the author, and with the author's own resources. The author declares that the research was conducted in the absence of any commercial or financial relationships that could be construed as a potential conflict of interest.

Copyright $\odot 2015$ Kundu. This is an open-access article distributed under the terms of the Creative Commons Attribution License (CC BY). The use, distribution or reproduction in other forums is permitted, provided the original author(s) or licensor are credited and that the original publication in this journal is cited, in accordance with accepted academic practice. No use, distribution or reproduction is permitted which does not comply with these terms. 